\title{
Simvastatin as a Potential Disease- Modifying Therapy for Patients with Parkinson's Disease: Rationale for Clinical Trial, and Current Progress
}

\author{
Camille B. Carroll ${ }^{\mathrm{a}}$ and Richard K.H. Wyse $\mathrm{e}^{\mathrm{b}, *}$ \\ ${ }^{a}$ Plymouth University Peninsula Schools of Medicine and Dentistry, Plymouth, UK \\ ${ }^{\mathrm{b}}$ The Cure Parkinson's Trust, London, UK
}

Accepted 7 October 2017

\begin{abstract}
Many now believe the holy grail for the next stage of therapeutic advance surrounds the development of diseasemodifying approaches aimed at intercepting the year-on-year neurodegenerative decline experienced by most patients with Parkinson's disease (PD). Based on recommendations of an international committee of experts who are currently bringing multiple, potentially disease-modifying, PD therapeutics into long-term neuroprotective PD trials, a clinical trial involving 198 patients is underway to determine whether Simvastatin provides protection against chronic neurodegeneration. Statins are widely used to reduce cardiovascular risk, and act as competitive inhibitors of HMG-CoA reductase. It is also known that statins serve as ligands for PPAR $\alpha$, a known arbiter for mitochondrial size and number. Statins possess multiple cholesterol-independent biochemical mechanisms of action, many of which offer neuroprotective potential (suppression of proinflammatory molecules \& microglial activation, stimulation of endothelial nitric oxide synthase, inhibition of oxidative stress, attenuation of $\alpha$-synuclein aggregation, modulation of adaptive immunity, and increased expression of neurotrophic factors). We describe the biochemical, physiological and pharmaceutical credentials that continue to underpin the rationale for taking Simvastatin into a disease-modifying trial in PD patients. While unrelated to the Simvastatin trial (because this conducted in patients who already have PD), we discuss conflicting epidemiological studies which variously suggest that statin use for cardiovascular prophylaxis may increase or decrease risk of developing PD. Finally, since so few disease-modifying PD trials have ever been launched (compared to those of symptomatic therapies), we discuss the rationale of the trial structure we have adopted, decisions made, and lessons learnt so far.
\end{abstract}

Keywords: Parkinson's disease, Simvastatin, disease modification, clinical trial

\section{INTRODUCTION}

Parkinson's disease (PD) is a progressive neurodegenerative condition with age being the main risk factor for its development [1]. With longevity

${ }^{*}$ Correspondence to: Richard KH Wyse, Director of Research and Development, The Cure Parkinson's Trust, 120 Baker St, London W1U6TU, UK. E-mail: richard@cureparkinsons.org.uk. having increased in most Western countries, a conservative estimation in 2007 predicted that the global number of PD patients will increase to approximately 10 million by 2030 [2]. By 2010, there were approximately 630,000 PD patients in the USA, a figure that was thought set to double by 2040 [3]. However, recent figures suggest these striking predictions may themselves be substantial underestimates since the incidence rates for PD now appear to be 
increasing each decade [4]. While these figures are alarming in themselves, especially given the burden to patients and to their families, these demographics also demonstrate the massive impact on each country's healthcare services that PD brings.

For example, the costs in the USA of managing PD were estimated in 2013 at \$23 million, which is $\$ 38,000$ per patient per year [5], a figure to which must be added the additional $\$ 10,000$ per patient/family of indirect costs that their PD incurs them. Furthermore, PD patients get progressively more expensive to manage as their condition deteriorates over time. Accordingly, increasing annual healthcare costs per PD patient are associated with more advanced stages of the disease, with greater burden resulting from cognitive decline, increased non-motor symptoms and development of balance impairment and falls. Therefore there is a compelling need, shared by patients, families and healthcare systems alike, to identify a cost-effective approach to intercept disease progression, to slow, stop or even reverse neurodegeneration in a rapidly expanding global population of PD patients. It is projected that if PD disease progression could be slowed by just $20 \%$ it would overall save approximately $\$ 76,000$ per patient, rising to a saving of approximately $\$ 440,000$ per patient if PD progression could be stopped altogether [5]. Both these scenarios would translate to far better long-term quality of life for PD patients, as well as saving billions of healthcare dollars every year by all major Western countries. Currently, only symptomatic treatments are available to PD patients since no disease-modifying therapy has yet been demonstrated to be effective in slowing PD progression, which highlights what is currently a huge unmet need for the identification of effective neuroprotective PD therapeutics.

For this reason, the International PD Linked Clinical Trials initiative was established in 2012 with the specific aim of identifying disease-modifying treatments for PD that would slow, stop or reverse the neurodegenerative aspects of this condition. The International PD Linked Clinical Trials is run by a committee of 15 global PD experts who, under the stewardship of the Cure Parkinson's Trust, are tasked with selecting, and sending into appropriately-designed clinical trials, compelling new and repurposed therapeutics to evaluate their disease-modifying potential in various different populations of patients with PD. At their first ever committee meeting in 2012, 26 potential diseasemodifying candidate drug approaches for slowing
PD progression were evaluated. At that meeting, several of these therapeutics were prioritized to enter PD disease-modifying trials, and they have since entered, or have now recently completed (Bydureon), these clinical evaluations. On the basis of compelling biochemical, physiological and pharmaceutical arguments, coupled with a strong safety record, Simvastatin was one of the drugs prioritized at that meeting [6]. Accordingly, funds were subsequently raised and this Simvastatin clinical trial in PD patients was commenced in September 2015 [7]. This Simvastatin study is co-funded by the Cure Parkinson's Trust and the JP Moulton Foundation. This on-going 2 year trial involves 198 patients with mid-stage idiopathic PD and is currently being carried out in movement disorder units in 23 hospitals across the UK. Projected completion of this trial is in early 2020.

The current paper discusses the original biochemical, physiological and pharmaceutical rationale that led the committee in 2012 to agree that this trial was strongly merited to explore the disease-modifying potential of Simvastatin for treating PD. It also updates to October 2017 the rationale for conducting this trial in terms of our current understanding of the relevant mechanisms of action and biological targets of Simvastatin that continues to maintain our enthusiasm about the use of this therapeutic as a disease-modifying approach for patients with PD.

This paper also strives to achieve a balanced view of a range of conflicting epidemiological studies surrounding the use of statins for cardiovascular protection, and whether statin use for this purpose may increase or decrease PD risk.

Finally, this paper describes details about our ongoing Simvastatin trial and outlines the decisions made about its design, as well as aspects about patient selection, patient recruitment, the dose of Simvastatin chosen, investigator site selection, rationale on how the duration of the trial was chosen, and the choices of which patient outcomes are being measured.

\section{WHY DOES SIMVASTATIN REPRESENT A STRONG CANDIDATE TO BE A DISEASE-MODIFYING THERAPEUTIC FOR PATIENTS WITH PARKINSON'S DISEASE?}

What is the biochemical, physiological \& pharmaceutical rationale for testing Simvastatin in PD patients as a long-term disease-modifying therapy? 
Although statins have been widely adopted in millions of patients worldwide as cholesterol lowering drugs to reduce cardiovascular risk, a very wide range of laboratory studies (described below) coalesce to suggest that statins also modulate some of the important biochemical processes involved with driving neurodegenerative changes, and may therefore offer a beneficial long-term disease-modifying therapeutic approach to reduce neurological decline in PD patients.

Several laboratory studies have demonstrated multiple biochemical neuroprotective effects of statins in models of PD; these will be reviewed and discussed below. Simvastatin, like all statins, is a specific inhibitor of the rate-limiting enzyme in cholesterol biosynthesis, and it is one of the most effective of the statins in terms of crossing the blood-brain barrier, while Pravastatin shows almost no penetration [8]. In fact the permeability of different statins into the brain directly relates to the level of their individual lipophilicity $[9,10]$.

In addition to their original pharmaceutical use in lowering cholesterol, statins display multiple neuroprotective effects. For example, Selley [11] reported that Simvastatin prevents methyl-4-phenyl1,2,3,6-tetrahydropyridine (MPTP)-induced striatal dopamine depletion and protein tyrosine nitration in mice. Ghosh et al. [12] then found, at a dose of $1 \mathrm{mg} / \mathrm{kg}$ body weight/day (which is equivalent to the FDA-approved dose in adults), that Simvastatin enters the substantia nigra, inhibits the activation of p21(ras), suppresses the activation of NF-B, attenuates the expression of proinflammatory molecules, protects dopaminergic neurons, restores striatal fibers and dopamine levels, and improves locomotor function in an acute MPTP model of PD. They concluded by suggesting that statins are capable of slowing down the progression of neuronal loss in the MPTP mouse model.

In an excellent and extensive review, Roy and Pahan in 2011 [13] outlined the evidence for five separate pathways, each thought to be of relevance in PD neurodegenerative aetiopathogenesis, by which Simvastatin may improve dopaminergic neuronal survival :-

- suppression of proinflammatory molecules and microglial activation

- stimulation of endothelial nitric oxide synthase

- inhibition of oxidative stress

- attenuation of $\alpha$-synuclein aggregation

- modulation of adaptive immunity
One of the objectives of the current review is to update these biochemical and pharmaceutical findings to the present day to help give a perspective on the rationale of why a clinical trial testing Simvastatin as a potential disease-modifying therapeutic for patients with PD is currently underway. Below is our current interpretation (updated to October 2017) of the multiple cholesterol-independent biochemical mechanisms of action of Simvastatin as originally cited by Roy and Pahan in 2011 [13] that we believe specifically support the biochemical, physiological and pharmaceutical reasons underpinning this innovative clinical trial. We add to this 2011 list, the topic of the stimulation of increased expression of neurotrophic factors by statins which was not covered by Roy \& Pahan in 2011 but since then, in the context of neurodegenerative diseases, has shown also to be of considerable relevance to the other pleliotropic effects of statins mentioned above.

\section{Suppression of proinflammatory molecules and microglial activation}

In 2011, Roy \& Pahan [13] collated evidence that inflammation and oxidative stress represent important components in nigrostriatal degeneration in PD [14-20]. At that time it was already well established that cytokines were central to the inflammatory processes that accompany various forms of acute and chronic brain injury, and many research laboratories around the world had begun to focus with therapeutic intent on PD. Ghosh et al. [19] also notably found that NF-kappaB was activated within the substantia nigra pars compacta of PD patients and in MPTPintoxicated mice. Roy and Pahan [13] then discussed how statins might be harnessed to reduce neuroinflammation in a Parkinsonian context.

At that time, the evidence for this potentially important property of statins was that Pahan et al. [21] had already shown Lovastatin inhibits NF- $\kappa \mathrm{B}$, iNos expression and the proinflammatory cytokines, TNF- $\alpha$, IL-1 $\beta$ and IL-6 in lipolysaccharide (LPS)stimulated rat primary astrocytes. Adding to earlier work by Stanislaus et al. [22], Neuhaus et al. [23] using in cells taken from multiple sclerosis patients demonstrated that Simvastatin is more potent as an effective immunomodulatory agent than either Lovastatin and Mevastatin.

To add to this, Clarke et al. [24], building on the fact that they knew statins generate powerful anti-inflammatory effects in brain, reported that Atorvastatin exerts these effects via IL-4, and 
completely independent of its cholesterol-lowering actions. These results were supported by other findings $[12,25]$ which showed how p21(ras) inhibits the expression of iNOS by inhibiting the activation of NF-kappaB, while Pahan et al. [21, 26] demonstrated how farnesylation can impact on these biochemical processes, and how the sphingomyelin-ceramide signaling pathway is involved with stimulating the expression of iNOS via LPS- or cytokine-mediatedactivation of NF-kappaB in astrocytes. The current state of knowledge at that time on these aspects had been well described and summarized by van der Most et al. [27], after which Santiago et al. [28] then showed that Simvastatin protected striatal dopaminergic terminals against the neurotoxic damage caused by LPS, but not in an MPP+ toxic model. Liu et al. [29] have recently explored how the inflammatory responses in microglia may be controlled in PD-related models and postulated, that Nur77 may be a modulator of microglia-mediated dopaminergic neurotoxicity.

Building on earlier work which showed that statins protect neurons in models of long-lasting status epilepticus and seizures, Gouveia et al. [30] found that Lovastatin protectively decreased mRNA expression levels of the proinflammatory cytokines, IL-1 $\beta$, IL-6, and TNF $\alpha$ in hippocampal neurons during experimental status epilepticus. Using a mouse model of Alzheimer's disease (AD), Kurata et al. [31] found that, after 15-20 months of treatment, both Atorvastatin and Pitavastatin were protective of senile plaque formation, and that this protection was preceded by a reduction of proinflammatory events including levels both of activated microglia and TNF- $\alpha$. This supported earlier work by Tong et al. [32] who had found in amyloid precursor protein transgenic mice that Simvastatin attenuated inflammation, oxidative stress and reduced amyloid beta levels and the number of affected neurites. Simvastatin had also been shown to protect against tissue injury in the context of ischemia-reperfusion injury [33], and in a model of cardiopulmonary bypass to protect against cerebral and systemic inflammation, neuronal loss and memory impairment [34].

Using a 6-hydroxydopamine model of PD and a 3 week administration of Simvastatin, Yan et al. [35] presented evidence that NMDA receptor modulation, MMP9 (matrix metalloproteinase-9) and TNF- $\alpha$ by Simvastatin could partially explain its anti-inflammatory, neuroprotective effects. Using a similar model of PD, Kumar et al. [36] then found in a mixed behavioral and biochemical study that Atorvastatin $(20 \mathrm{mg} / \mathrm{kg})$ and Simvastatin $(30 \mathrm{mg} / \mathrm{kg})$ were both protective of weight loss, locomotor activity, and also decreased levels of the inflammatory cytokines, TNF- $\alpha$ and IL- 6 that are characteristic of this model. They also found that these statins restored the deficits in mitochondrial enzyme complex activity that are also generated in their 6-hydroxydopamine model.

The notion that mitochondrial function might be involved with the anti-inflammatory action of statins was also highlighted by Esposito et al. [37] in a completely different model, that of spinal cord injury (which also displays inflammation, neutrophil infiltration, nitrotyrosine formation, pro-inflammmatory cytokine expression, and nuclear factor (NF)- $\kappa \mathrm{B}$ activation). They showed that PPAR- $\alpha$ (a major arbiter of mitochondrial size and number) contributes to the anti-inflammatory activity of Simvastatin. Specifically, and describing their findings as the demonstration of a new mechanism for the action of statins, they showed that the anti-inflammatory properties of Simvastatin were substantially reduced in a PPAR- $\alpha$ knockout model. Since, as well as overall mitochondrial function, the PPAR-alpha nuclear receptor also regulates genes involved with inflammation and oxidative stress, it is of particular interest that they found PPAR- $\alpha$ mediates the antiinflammatory effects of Simvastatin in vivo models of acute neuroinflammation. This built on their earlier observation [38] that Simvastatin similarly worked in synergy with PPAR- $\alpha$ to protect cellular damage caused by systemic inflammation in a model of multiple organ failure. A recent report by Zhou et al. [39] expands Esposito's findings in that they showed Simvastatin is both neuroprotective and inhibits secondary inflammatory damage by markedly downregulating the expression of the proteins (NF) $-\kappa \mathrm{B}$, TLR4 and IL-1 $\beta$.

$\mathrm{Xu}$ et al. [40] studied how Simvastatin affects 6-hydroxydopamine-lesioned PC12 through regulation of PI3K/AKT/caspase 3 and by modulating inflammatory mediators, and how it might be used therapeutically to treat patients with PD. In a cellular RNA study involving 6-OHDA administration, Yan et al. [41] explored the involvement of N-methylD-aspartic acid receptor 1 (NMDAR1) finding that Simvastatin inhibits the expression of NMDAR1, and of the cytokines, TNF- $\alpha$, IL- $1 \beta$, and IL- 6 , in a manner just as potent as using siRNA for the receptor. In a retinal cell model, Zhang et al. [42] reported that that Simvastatin inhibits apoptosis following IR-induced retinal injury by inhibition of the TNF- $\alpha / \mathrm{NF}-\kappa \mathrm{B}$ pathway. With a PD therapeutic perspective in mind, Zhang's findings should be 
seen in the context that Malu Tansey's group had previously described [43] how the TNF- $\alpha / \mathrm{NF}-\kappa \mathrm{B}$ pathway mediates chronic inflammation which, in turn may generate a reduction in Parkin levels, and thereby increasing the vulnerability for degeneration of the nigrostriatal pathway. They argued that chronic inflammation offers a clear biochemical mechanism which can promote the development of PD. Huang et al. [44] recently showed in multiple models that Simvastatin ameliorated memory deficits in patients with Alzheimer's disease as well as in laboratory models of $\mathrm{AD}$, and that it achieved this through reduction of mRNA expression of inflammatory cytokines and mediators as well as by improving neuronal survival, supporting earlier work by Wang et al. [45].

In summary, by directly inhibiting key inflammatory processes, Simvastatin may therefore represent a therapeutically beneficial disease modifying agent with considerable potential to reduce the rate of PD progression.

\section{Stimulation of endothelial nitric oxide synthase}

Roy \& Pahan [13] also collated robust evidence [14-15, 17, 21, 24-25] in 2011 which supported the view that the upregulation of endothelial nitric oxide synthase (eNOS) is generated by statins via suppression of mevalonate and concomitant activation of the PI-3 kinase-AKt pathway. This built on Flint Beal's supposition [46] that modulating eNOS might offer a valuable neuroprotective therapeutic approach for the treatment of PD. Statins inhibit iNOS expression, while in contrast, they stimulate eNOS-derived nitric oxide production, and this property appears biochemically unrelated to their ability to reduce cholesterol [47]. Statin-induced upregulation of eNOS can be reversed by geranylgeranyl pyrophosphate (but not by farnesyl pyrophosphate) which intimates [13] that Rac/Rho (rather than Ras) may be involved in the regulation of eNOS. Fulton et al. [48] and Skaletz-Rorowski et al. [49] demonstrated that Akt phosphorylates eNOS, while mevalonate inhibits phosphatidylinositol-3 kinase and thereby reduces Akt activation. As statins lower mevalonate levels (via inhibition of HMG-CoA reductase) it therefore seems likely that reduction of mevalonate may trigger increased eNOS production, and thereby increasing NO levels. Atorvastatin has been shown $[50,51]$ to promote NOS-derived nitric oxide production by reducing expression of caveolin-1, and the therapeutic implications of these HMG-CoA reductase effects of statins are still being actively clarified in cardiovascular medicine [52, 53].

A recent review by Saeedi Saravi et al. [54] focuses more specifically on the potential relevance of the mevalonate pathway to the potential therapeutic benefit that statins may offer in protecting against long term neurodegeneration in PD patients. Bezard's group [55] now consider downstream modulation of the sterol regulatory element-binding protein 1 (SREBP-1) pathway to be important in inducing phenotypic changes in dopaminergic cells, including increases in cell growth, synaptic connections and protein expression. They have recently presented additional data on this that supports a potential protective role of statins in PD [56]. Since SREBP-1 (and SREBP-2) regulates promotor activity of PCSK9 [57] there is therefore a clear link, with therapeutic implications, between SREBP-1 and PCSK9, and it was recently shown that Simvastatin increases PCSK9 expression $[58,59]$ which may be therapeutically relevant [60-63].

Sun et al. [64] showed in a cardiovascular context that eNOS is a direct target of miR-155. Inflammatory cytokines such as TNF- $\alpha$ increase miR-155 expression and inhibition of miR-155 reverses TNF$\alpha$-induced downregulation of eNOS expression. They found that Simvastatin decreased TNF- $\alpha$ induced upregulation of miR-155 and ameliorated the effects of tumor necrosis factor- $\alpha$ on eNOS via the mevalonate-geranylgeranyl-pyrophosphateRhoA signaling pathway.

Pierucci et al. [65] reviewed in 2011 the promise and opportunities of harnessing the NOS system to treat PD, essentially building on the work by Hoang et al. [66] who assessed the aspects and extent of the nitrative damage, including in nuclear and mitochondrial DNA, that is caused in an MPTP model of PD, and in a NOS knockout model, and from which they concluded DNA damage may contribute to the overall neurodegenerative process in PD. Peter Jenner's group [67] found evidence of a major role for i-NOSmediated nitrative stress in microglia in their MPP+ model of PD, which they concluded had important implications for developing neuroprotective strategies for PD, an argument which was further supported by Tripathy et al. [68], and also recently reviewed by Jiménez-Jiménez et al. [69] from the perspective of studies both in PD patients, and in various PD models.

Li et al. [70] reported in 2015 how Simvastatin is therapeutically beneficial following LPS-induced experimental lung injury, showing it had a protective effect by alleviating lung injury via decreasing 
iNOS levels. This ties in with the earlier findings by Pahan et al. [21] who, as described above, had already demonstrated that Lovastatin inhibits NF- $\kappa \mathrm{B}$, iNOS expression and the proinflammatory cytokines, TNF- $\alpha$, IL-1 $\beta$ and IL-6 in LPS-stimulated rat primary astrocytes.

Therefore, as well as its beneficial effects through suppression of proinflammatory molecules and reduction of microglial activation (as outlined in the previous section), Simvastatin also appears to offer substantial long-term disease-modifying benefits for PD patients on the basis of decreasing microglia iNOS levels and reducing chronic nitrative stress.

Along with the continued research into how NOS may contribute to the neurodegenerative process in PD, and may thus offer a therapeutic opportunity, such as using Simvastatin, to delay PD progression, a parallel line of research has explored how NOS might be modulated for therapeutic benefit in treating a widespread clinical complication experienced by many PD patients on long-term dopaminergic support, that of L-DOPA-induced dyskinesias. How NOS inhibitors might be employed in the treatment of dyskinesias has been explored in experimental studies using various PD models [71-74], and is clearly showing promise for clinical translation for the treatment of dyskinesias in PD patients. The basis for this $[75,76]$ is that when inhibitors of the MAPK signaling cascade impede the inappropriate dyskinesia-inducing response of striatal neurons this offers considerable evidence that MAPK inhibitors may offer therapeutic efficacy in reducing incidence and/or severity of dyskinesias experienced by PD patients.

The isoprenylation of Ras is inhibited by statins which underpins their ability to curb the stimulation of ERK 1/2 MAP kinases, and Schuster et al. [77] found that Lovastatin reduces the number and severity of dyskinesias in their 6-OHDA model of PD. In particular, Tison et al. [78] found that Simvastatin was indeed effective in reducing dyskinesias in a monkey model of PD, but only at high doses that would be incompatible with their long-term administration in man, and which were 3-6 times higher than is being used in the current clinical trial of Simvastatin in PD patients (see below).

\section{Inhibition of oxidative stress}

Roy \& Pahan [13] reviewed the evidence for the involvement of statins in inhibiting the process by which oxidative stress contributes to neurodegeneration in PD, particularly focusing on the roles of nicotinamide adenosine dinucleotide and Rac, collating evidence that NADPH oxidase is vital in terms of attrition of dopaminergic neurons. In fact it was already known that nigral NADPH oxidase is upregulated in MPTP mice, but that, conversely, this toxin had no effect on dopaminergic neurons in gp91phox $(-/-)$ mice $[79,80]$. Building on the review by van der Most et al. [27], Roy \& Pahan [13] provided evidence that the inhibition by statins of the geranylgeranylation of Rac leads to reduced NADPH oxidase-mediated generation of superoxide, which they interpreted as evidence statins may attenuate oxidative stress by diminishing the production of reactive oxygen species both in the substantial nigra of MPTP mice, and in PD patients via this biochemical process.

Since then, much research has focused on the role of Nrf2 (nuclear factor erythroid 2-related factor 2) in oxidative stress [81, 82], and how, in several therapeutic areas, including PSP and PD [83], agerelated macular degeneration [84], oncology [85, 86], cardiovascular disease [87, 88], arterial calcification [89], spinal cord injury [90] and radiation dermatitis [91], this emerging biochemical insight might be manipulated to therapeutic advantage. Nrf2 is a cytoprotective master regulator of the transcriptional response to oxidative stress; it has a rapid turnover, and its role in neurodegenerative diseases has been well described by Gan and Johnson [92], and its diversity of actions and control with respect to mitochondrial function were recently well reviewed by Holmstrom et al. [93], and also by DinkovaKostova et al. [94]. When reactive oxidative species are at low levels, nuclear Nrf2 is suppressed by the inhibitory protein, KEAP1, which sequesters Nrf2 in the cytoplasm to prepare it for proteasomal degradation [95, 96], and which maintains Nrf2 at a relatively low steady state level. However, increasing levels of reactive oxidative species influence KEAP1 in a way that progressively impairs its ability to target Nrf2 for degradation. A link between Nrf2, MAPT expression and the risk of PD has recently been postulated by Wang et al. [97], and may possibly offer a mechanistic glimpse of why tau/MAPT repeatedly appears in large-scale GWAS studies of PD patients $[98,99]$ yet its role in the generalized risk of developing PD, and its specific role in neuroinflammation with regards to PD, are both poorly understood [100].

Several agents (particularly Nrf2 activators), which act on these biochemical pathways (by upregulating antioxidant, anti-inflammatory, mitochondrial 
biosynthetic, apoptotic mediator and cytoprotective genes) have promising potential for the long-term protection from neurodegeneration in PD patients. These include monomethylfumarate [101], dimethylfumarate [102], gliptins [103] and the triterpenoid, RTA-408 [85], each of which have already been prioritized by the International PD Linked Clinical Trials committee to enter clinical trials in PD patients to determine their disease-modifying potential. As a practical therapeutic approach in neurology, much of the new understanding of the protective potential of activating Nrf2 resides in these emerging publications and it is being rapidly translated into disease-modifying agendas in PD, as well as in other therapeutic areas. Urate probably also acts via the Nrf2 antioxidant response pathway [104] and is currently being tested (using oral inosine) in a Phase III trial in 270 PD patients to assess its diseasemodifying potential over a treatment duration of 2 years [105]. To add to all the other biochemical actions of statins outlined in this review we can add another LCT-prioritized drug, Simvastatin, to this important list of Nrf2 activators that may all have the potential to be used clinically to slow neurodegeneration in PD patients. In 2014 Abdanipour et al. [106], studying PGC- $1 \alpha$ and Nrf2 expression on cell survival and apoptosis demonstrated that Lovastatin protects bone marrow stromal cell-derived neural stem cells against oxidative stress-induced cell death, and suggested it as a candidate for the treatment of neurological diseases that involve oxidative stress. Since then, several papers have added further support to the view that statins act as Nrf2 activators. Wu et al. [107] recently reported that Atorvastatin reduces damage in liver injury when exposed to inflammatory stress, citing loss of the adaptive antioxidant response mediated by Nrf2 as the basis for the biochemical mechanism involved. Simvastatin was found by Jang et al. [108] to induce heme oxygenase-1 via direct activation of Nrf2 in human colon cancer cell lines. Ferraro et al. [109] studied the effects of Simvastatin in both lung inflammation and in a human neuroblastoma cell line and concluded that Simvastatin may provide neuroprotection against neurotoxicity via Nrf2 independently of its ability to inhibit cholesterol synthesis. Furthermore, Yeh et al. [110] demonstrated that the well known effect of statins to protect against atrial fibrillation was generated by the activation of Akt/Nrf2/heme oxygenase-1 signaling.

Hsieh et al. [111] was the first to show that iron production from Heme oxygenase-1 activity may play an important role in the increased apoptosis in response to glucose deprivation in neuronal cells pretreated with Simvastatin which acted by inducing Heme oxygenase-1, a process which was mediated by Nrf2. They found in neuronal cells that the iron chelator, desferrioxamine, blocked apoptosis, which suggested that iron production from Heme oxygenase-1 activity might drive increased apoptosis in situations of glucose deprivation in neuronal cells that had been pretreated with Simvastatin. Two PD trials also prioritized by the international PD Linked Clinical Trials committee in 2012 are underway to test iron chelator therapy as a potential disease-modifying treatment for patients with PD. One trial involves 338 early-stage PD patients who are not currently taking antiparkinsonian medication (disease duration less than 18 months) and who are taking the iron chelator, Deferiprone [112], and the second dose-finding trial [113], also using Deferiprone, is comprised of 140 PD patients who have been diagnosed with PD within the last 3 years and who are currently taking antiparkinsonian medication.

\section{Attenuation of $\alpha$-synuclein aggregation}

In their 2011 review of the potential for using statins to treat PD, Roy and Pahan [13] summarized the knowledge at that time relating to how alphasynuclein impacts on dopaminergic toxicity and cell loss, motor deficits, the synthesis of cholesterol, and the deposition of alpha-synuclein-rich Lewy bodies in the substantia nigra. They concluded that, since statins suppress the release of proinflammatory molecules from activated glial cells (see above), it is likely they should also subdue malformed alphasynuclein-mediated glial cell activation in a manner that is completely independent of cholesterol. As with all the other sections in this review, much has moved on over the past 6 years. A current view, held by many (but not in 2011) is that malformed alpha-synuclein is capable of cell-to-cell transmission and that this may underpin the development of PD throughout the body, but particularly involving spread from the enteric nerves, and/or olfactory bulb, to the substantia nigra, raphe, locus coeruleus, the cortex and several other important anatomical sites which each contribute in their own way to the range of PD symptoms we see clinically [114-118].

Roy and Pahan [13] reflected on how Lovastatin, Simvastatin and Pravastatin each generate large reductions in alpha-synuclein accumulation both in a transfected neuronal cell line, and in primary human neurons [119], and that oxidized 
cholesterol even promotes increased alpha-synuclein aggregation [120]. This observation has recently been somewhat supported by Eriksson et al. [121] who interpreted their findings in a neuroblastoma cell line exposed to $\mathrm{MPP}^{+}$to reason that high cholesterol in PD stimulates the accumulation of alpha-synuclein.

Once Lovastatin was also shown [122] to reduce alpha-synuclein accumulation and aggregation in transgenic models, it was logical to contemplate that, since statins lower cholesterol levels, then they may therefore directly reduce the aggregation of alphasynuclein in PD patients. Koob et al. concluded that, while it was known as early as 2006 [123] that, once mutated, alpha-synuclein causes a much stronger glial cell inflammatory response, but that since statins reduce the expression of these proinflammatory molecules they may well be found beneficial as a long-term treatment for patients with PD. Given the knowledge available at that time, Roy and Pahan [13] therefore posed the logical question; do statins suppress mutated alpha-synuclein-mediated glial cell activation in a manner that is completely independent of cholesterol? Several papers, mostly published since then, have gone some way to answering that question [24, 124-131] - the widely-held consensus answer is definitely yes, although there is still slightly less clarity on the mechanistic details than we might have wished for.

\section{Modulation of adaptive immunity}

Statins have been repurposed into several diseases where innate and adaptive immunity and endothelial damage play an important role [132]. To date, statins have been specifically tested and used in atherosclerosis [133], multiple sclerosis [134, 135], rheumatoid arthritis [136], Behcet's disease [137], and Kawasaki disease $[138,139]$ in many cases with very promising results. It was pointed out in the review by Roy \& Pahan [13] that effector T cells may exacerbate disease progression (which can be demonstrated in post mortem PD brains), while regulatory $\mathrm{T}$ cells (Tregs) tend to occupy a protective role. It has been found that T-cell responses in an MPTP model of PD add to the rate of neurodegeneration [140-142] while conversely, Tregs have been shown to be protective in an MPTP model of PD [143], and the reasons behind this duality have previously been discussed by Mosley et al. [144] and, since Tregs can be modulated in vivo, this gives strong support to the use of an immunomodulatory approach to treat PD. In 2010, Reynolds et al. [145] demonstrated that natural
Tregs reversed the $\mathrm{T}$ cell nigrostriatal degeneration caused by malformed alpha-synuclein, proposing that this observation forms a sound rationale for future PD immunization strategies. This approach has been reviewed and expanded upon by several with considerable clarity and insight [124, 130, 146, 147], and most recently by Gendelman and Mosley [148] who discussed approaching this topic in therapeutic terms by postulating simultaneously to seek enhancing the suppressive function of Tregs, while downregulating proinflammatory cytokine production. They balanced and tempered this by recognizing that immune system activation is also necessary in order to clear debris to help sustain and restore damaged neurons. They offered 'mounting and strong evidence' that immune transformation can affect the pathogenesis of neurodegenerative diseases, and that modulation of the inflammatory response, while restoring a homeostatic immune system via immunopharmacological strategies, may lead to new therapeutic opportunities for PD and other neurodegenerative disorders.

Acting as a cytokine and neuropeptide which impacts on immune responses, Vasoactive Intestinal Peptide (VIP) induces Tregs. The neuroprotective capability of Tregs is mediated through $\mathrm{TH} 17$, and it has been suggested that shifting the balance between effector and regulatory $\mathrm{T}$ cell activity by adaptive immune regulation of glial homeostasis could be used to attenuate neurotoxic inflammatory events [149]. By peptide modifications similar to those for GLP1 agonists that have given them greater potency and much longer metabolically stable half-life in blood than the native hormone, Olsen et al. [150] developed an analogue of VIP and showed it to be an effective immunomodulatory agent in an MPTP model of PD. They concluded by stating they had provided "strong evidence" that VIP receptor agonism has the potential to slow the pathogenesis of PD through modulation of the inflammatory response. This builds on the earlier observation by Brachmachari and Pahan [151] who, and citing Foxp3 as a master regulator in Treg formation and function, discovered that Simvastatin upregulates Foxp3 by inhibiting nitric oxide production, going on to suggest that Treg enrichment by Simvastatin may help to protect dopaminergic neurons in the substantia nigra.

\section{Increased expression of neurotrophic factors}

This potential biochemical effect of statins was not covered in the earlier review by Roy \& Pahan [13]. Hernandez-Romero et al. [152], as well as demon- 
strating the potency of Simvastatin in markedly reducing inflammatory responses in LPS-induced PD rats, including interleukin-1, TGF- $\alpha$ and iNOS (as have several other groups, as described above), also found that Simvastatin stimulated the activation of the neurotrophic factor, BDNF. This suggests there may be a profoundly neurogenic aspect to the mechanism of action of Simvastatin in dopaminergic neurons. This was followed up by Wu et al. [153] who showed that Simvastatin increases the hippocampal expression of BDNF and VEGF in a model of brain injury.

They concluded that the neurorestorative effect of Simvastatin they observed was probably mediated via the Akt-mediated signaling pathway, which thereby upregulated expression of growth factors, thus stimulating via neurogenesis the restoration of cognitive function they observed with Simvastatin. They employed a similar dose to that used in our current clinical trial of Simvastatin in PD patients (see below). It was then reported [154] in a model of spinal cord injury that Simvastatin generated significantly improved locomotor recovery, and this improvement was ascribed to the higher levels of expression of BDNF and GDNF which were observed in this study after administration of Simvastatin. This contention was further supported when it was reported [155] that both Simvastatin and Atorvastatin increased the expression of BDNF, VEGF and NGF, as well as activation of the Akt-mediated signaling pathway, in an experimental model of intracerebral hemorrhage. Furthermore, it was shown [156] that Simvastatin modulates the profile of the release of cytokines and trophic factors from microglia, (particularly interleukin- $1 \beta$, TNF- $\alpha$, and BDNF) through a mechanism that is cholesterol-dependent, and which went some way to explain previously confusing contradictions in laboratory results. Rana et al. [157] then reported that Simvastatin increased expression of BDNF exon-IIC transcripts in stressed mice. Wang et al. [158] then reported that, in A $\beta 25-35$-mice, Simvastatin is protective of neurogenesis through reduction of farnesyl pyrophosphate level which then generates $\alpha 7 \mathrm{nAChR}$-cascading PI3K-Akt and increased levels of BDNF. Next, Gao et al. [159] demonstrated that Simvastatin significantly increases the levels both of BDNF and GDNF in a model of spinal cord injury, and then went on to show that Simvastatin also reduces neuronal apoptosis while promoting locomotor recovery in this model [160]. It was recently shown [161] that Simvastatin promoted the neurogenesis and migration of neural stem cells with a mode of action involving the ROCK/CGTase pathway. Simvastatin has also recently been demonstrated to improve peripheral nerve regeneration and functional recovery in an experimental model of sciatic damage that involves elevation of levels of GDNF and several other growth factors [162]. Earlier this year, it was reported [163] that Atorvastatin increased serum BDNF levels and improved functional recovery (modified Rankin and Barthel scales) in patients following atherothrombotic stroke.

It had previously been highlighted [20] that the Nurr1/CoREST pathway in microglia and astrocytes protects dopaminergic neurons from inflammatory damage, and this is thought to be particularly relevant here because Nurr1 activity is known to be closely related to GDNF activity [164]. Wang et al. [158] also demonstrated that Simvastatin induces autophagy by inhibiting the mTOR signaling pathway. In 2015, Roy et al. [165] then took a step forward to help tie the various threads together in reporting that statins serve as ligands for PPAR $\alpha$ and ascribed the neurotrophic action of statins to be via the PPAR $\alpha$-CREB pathway. Until then there had been no receptor protein identified for statins (they exert their lipid-lowering actions quite differently, more structurally, as competitive inhibitors of HMG-CoA reductase).

Finally, and here focusing on PD, unlike most of the other neurological models described in this section from which we are definitely able to draw useful parallels, Castro et al. [166] reported on how Atorvastatin in an intranasal PD rat model caused a significant increase in striatal and hippocampal levels of nerve growth factor, adding that their findings 'extend the notion of the neuroprotective potential of Atorvastatin and suggest that it may represent a new therapeutic tool for the management of motor and non-motor symptoms of PD', while in 2016, Tan et al. [167] showed in an LPS model of PD that Simvastatin restored the expression of BDNF, as well as replicating earlier findings by many groups that it reduces oxidative stress and improves nigral function.

\section{EPIDEMIOLOGICAL STUDIES ON THE USE OF STATINS AND THE RISK OF PD}

The purpose of this section is not intended as a critical appraisal of epidemiological research in this area, nor to generate data synthesis (in fact others have previously attempted to do this - see below), but rather to provide a catalogue, and a context, of published studies. 
Valid interpretation of published studies has been consistently confounded by the core reason why statins are taken, i.e., to reduce high levels of cholesterol, which in turn means there is inevitably a high correlation between the two explanatory variables, statin use and blood cholesterol levels. Partly because of this confounding inter-relationship, there is currently no clarity about whether statin use is protective of an individual developing PD, has no effect, or makes it more likely that an individual may develop the disease.

Most would agree that the hypothetical risk of a healthy individual acquiring PD through taking a particular medication, represents a very different scenario to using that same medication to treat the disease once it has already developed. Nevertheless, it is appropriate to discuss here, and bring a balance to, the various studies that have either linked the taking of statins to protecting healthy individuals against developing PD, or the converse.

We re-emphasize this ongoing epidemiological debate is actually of questionable relevance to patients who already have PD but it is appropriate in terms of our on-going trial of Simvastatin to use this opportunity to give a balanced scientific review of the viewpoints, the available evidence, and to highlight strengths and weaknesses in published papers in this area of research.

First, it is important to make the point that, since the initial isolation of statins from microorganisms in the 1970s, there has been a huge growth in their specific use in primary and secondary prevention of various forms of cardiovascular disease. In 2016, the US Preventative Services Task Force advised the use of statins for people between 40 and 75 years old who carry at least one risk factor for heart disease, and who have more than a $10 \%$ risk of heart disease [168]. Similarly, the UK National Institute for Health and Clinical Excellence has endorsed the use of statins in those with an estimated $10 \%$ risk of developing cardiovascular disease over the next decade [169]. The nature, interactions and pharmacokinetic relationships between cholesterol, apolipoproteins and statins were well described from a neurological perspective in a Cochrane review [170, 171] as a part of an original, then updated, analysis to consider the possible use of statins in the context of dementia prevention or treatment. They found 'insufficient evidence to recommend statins for the treatment of dementia'. Many PD patients develop cognitive impairment, but while none of those in that meta-analysis were PD patients, a recent paper by Deck et al. [172] found that PD patients taking statins performed better on tests of global cognition, semantic fluency and phonemic fluency. Furthermore, although it is known that statins increase HDL and apolipoprotein A1 levels [173, 174], and that lower apolipoprotein A1 levels are associated with later stages of PD progression, Deck did not find that baseline apolipoprotein A1 levels correlated with any baseline neuropsychological measures.

Turning now to the question of whether the use of statins may positively or negatively influence the risk of developing PD, in 2006 and citing that epidemiologic investigations had revealed an association between low LDL-C levels and the risk of PD, with several studies previously having suggested a role of lipid and cholesterol metabolism in the pathogenesis of PD, de Lau et al. [175], studying $>6000$ patients, felt there might well be a role involving lipids in the pathogenesis of PD, and suggested that this provided support for the notion of an important role of oxidative stress in the pathogenesis of the disease.

An extensive review of patients in the Veterans Affairs healthcare system then found Simvastatin (but not Atorvastatin or Lovastatin) use was associated with a strong reduction in incidence of dementia and PD [176]. Wahner et al. [177] then found that all statins are inversely associated with PD (except for Pravastatin). They observed a higher frequency of statin use among controls versus PD cases. The strongest protective association between statin use and PD was observed in long-term ( $>5 \mathrm{yr}$ ) statin users. Huang et al. [178] then reported the results of a small epidemiological study of 124 PD patients and 110 controls which inferred that low LDL-C may be associated with a higher occurrence of $\mathrm{PD}$, and that statin use for prophylactic cardiovascular protection may lower PD occurrence. What Huang did not report is whether their patients had low LDL levels prior to their diagnosis of PD, nor whether their LDL levels decreased after this diagnosis. Therefore, since statins are effective at lowering LDL cholesterol levels, it may well be that their study design intrinsically confused cause with effect. What is more is that this research was vastly underpowered in the sense that fewer than 20 of the 124 PD patients in this study were actually taking statins so the results cannot be viewed as reliable. Becker at al then reported in a case-control analysis involving 3637 PD patients and 3637 controls that the long-term use of statins or fibrates was not associated with a substantially altered relative risk of developing PD [179]. 
The same year, a study of approximately 50,000 Finnish citizens, with their baseline serum total cholesterols stratified into five groups, reported that those individuals with the highest levels of cholesterol were almost $90 \%$ more likely to develop PD than those with the lowest levels of cholesterol [180], concluding that, in subjects under 55 years of age, our 'large prospective study suggests that high total cholesterol at baseline is associated with an increased risk of Parkinson's disease'.

A retrospective study involving a cohort of 419 PD patients, showed that in PD patients who received either a statin or a fibrate, their mean age of disease onset was delayed by nearly 9 years when compared with PD patients who were not taking any lipid-lowering treatment [181]. They also found the increase in the levodopa-equivalent daily dose over 2 years was significantly smaller in the group taking a statin $(+24 \mathrm{mg})$ than in the matched control group $(+212 \mathrm{mg})(p=0.004)$, whereas the UPDRS motor score progression was similar. Their conclusion was that lipid-lowering drugs may have a disease modifying effect.

The 2011 DATATOP study [182] then provided evidence that higher total serum cholesterol concentrations may be associated with a modest slower clinical progression of PD. The same team at Harvard, using 12 years of patient follow-up, and following 644 documented incident cases of PD, then reported [183] that regular use of statins was associated with a modest reduction in PD risk. They suggested that "the possibility that some statins may reduce PD risk deserves further consideration".

The following year Undela et al. [184] conducted a robust meta-analysis of published healthy subjects and found, across five separate case-control studies $(n=43,526)$ and three cohort studies $(n=1.4$ million), that statin use reduced an individual's risk of getting PD by $23 \%$ ( $p=0.005)$, but no such effect was found for long-term statin use. They substantiated their findings by conducting further sensitivity analyses and concluded that their results 'suggest a decreased relative risk of PD in statin users as identified by a combined meta-analysis of eight observational studies'. Friedman et al. [185] then reported their findings following 94,308 (initially) non-statin users who did not have PD. By the end of their study, there had been 1035 incident cases of PD. Furthermore, 29,714 participants $(31.5 \%)$ had started using statins for a minimum of 6 months during the study period. This statin use was associated with a significant decrease in the incidence of PD $(p=0.001)$, while no association was found between baseline LDL-C levels and PD risk. Friedman felt their results provided evidence relating to a lower incidence of PD among statin users.

This contention was further supported by a report from Taiwan [186] following for several years 43,810 individuals who had started taking a statin, and backed up by an excellent commentary by Tan and Tan, [187]. It was found that continuation of taking lipophilic statins was associated with a decreased incidence of PD, whereas taking hydrophilic statins appeared not to generate this benefit.

Then, Huang et al. [188] reported results of a prospective study involving 15,291 individuals without PD and mostly who were not statin users at study commencement. Over approximately a decade statin usage had increased to $11.2 \%$ of the study population, and there were 56 incident cases of PD. As in their 2011 paper [182] they reported that higher total cholesterol was associated with a lower risk of developing PD, even after adjustment for statin use. Unlike their earlier studies they calculated that statin use may be associated with a higher risk of acquiring PD which added further uncertainty to this topic, and also attracted considerable journalistic interest.

To try to gain some clarity on whether statins were protective or not in terms of initially developing PD, Bai et al. [189] and Sheng et al. [190] both published extensive meta analyses of relevant results to date. Bai's meta-analysis involved 3,513,209 individuals and included 21,011 incident cases of PD. Sheng's meta-analysis involved 2,787,249 individuals. The results of both studies were in complete agreement that statin use was associated with a much lower risk of PD $(p=0.001)$ and that sensitivity analyses confirmed the robustness of these results. They found that statin use was less protective of PD in North America than in other geographies, which is something that may account for some of the conjecture and mixed results that had been published previously. Furthermore, and adding to this complexity in terms of confounding interpretation of statin use in the context of PD epidemiology, Clark et al. [191] found that the frequency of treatment success in dyslipidemia management was significantly lower in African American patients in the USA than in non-Hispanic white patients, while Yood at al [192] found that African American patients initiating statin therapy are less likely to achieve LDL goals, even after controlling for adherence differences and other factors, and suggested that this group may require different pharmacologic management. 
Huang's group then reported in 2016 [193] that higher levels of LDL-cholesterol were associated with improved executive set shifting and fine motor scores in PD patients, but not in healthy controls. This small study (64 PD cases) did not contain many statin users to be meaningful on interpreting this aspect but interestingly, they hypothesized from their results that there may possibly be an association between cholesterol and cognition that is nigrostriatal-based while very fairly pointing out that they could not currently ascertain whether this relationship was causative, reverse-causative or a parallel process.

Earlier this year Huang's group [194] used a large US claims database of people who had chosen to enroll in private healthcare insurance schemes in order to interrogate this team's earlier 2015 contention [188] that statin use may be linked to a higher risk of PD. This time they included 21,599 individuals who, during the period of their analysis generated 2322 incident cases of PD who, for statistical analysis, were then matched with an identical number of healthy controls. Consistent with several earlier studies, they found that higher levels of cholesterol was associated with a lower risk of PD. They also reported that the use of statins (especially lipophilic statins) was associated with higher risk of PD.

Rozani et al. [195] recently published a 232,877 population-based cohort study of new statin users in whom 2,550 developed PD during a mean follow-up of 7.6 years. The study was unusual in that throughout this time the researchers comprehensively made multiple repeated measurements both of statin exposure and LDL-levels. Contrary to Huang's findings [188, 194], and agreeing with the results of many other studies [176-179, 181, 183-187, 189, 190] they found no association between annual statin adherence and PD risk regardless of age, or type of statin taken.

Understandably, those taking statins, or consider taking a statin, to reduce their cardiovascular risk want to know whether this choice would also bring them an increased likelihood of developing PD? This is a very different question to whether a statin might represent a disease-modifying therapeutic for use in patients who have already developed PD, and our ongoing 2 year clinical trial involving approximately 200 PD patients seeks specifically to determine whether Simvastatin slows PD progression.

As can be seen above, there have been several epidemiological studies investigating whether there may be an association, protective or otherwise, of statin use in relation to subsequent development of PD. These have recently been evaluated in a systematic review and meta-analysis by Bykov et al. [196] that helpfully discusses the methodological strengths and weaknesses of each of these earlier epidemiological studies. It is fair to say that the methodologies utilized in the epidemiological papers cited above all have limitations. Association does not imply causation. Bykov found that overall there seems to be a protective effect of statins against development of $\mathrm{PD}$, but that if cholesterol levels are adjusted for, then this protective effect disappears, and there is no association one way or the other with PD development. The authors also describe some of the limitations of epidemiological study design, including the 'healthy user' and 'immortal time' biases among others [197].

A brief description of the key findings from many of the various types of epidemiological studies that have attempted in recent years to determine whether the use of statins is positively or negatively associated with PD risk are summarized in Table 1.

With regard to Huang's most recent publication suggesting that Simvastatin may facilitate development of PD [194], there are some key limitations which merit highlighting: large sectors of the population were not represented in the database that was analyzed (particularly the elderly, i.e., over $65 \mathrm{~s}$, were excluded); and only those with private health insurance were included. It is possible that some patients in this study were misdiagnosed because the clinical details of the participants, and diagnostic confirmation, was not available to the researchers. The authors found that PD was more likely to be diagnosed within the first year or so of starting Simvastatin. However, it is well acknowledged that PD starts at least 5 years, if not 10 years before diagnosis; it has also been demonstrated by others that healthcare contacts increase in the year or two prior to diagnosis, which could be what led to their being prescribed a statin. It is well known that vascular risk factors increase risk of dementia, and it would not be unreasonable to suppose that the same might hold true for other neurodegenerative diseases. It is likely that most people taking a statin were started on it because of their vascular risk, and that this might have been the contributory factor that was identified in the study. Indeed, a UK cohort study has demonstrated worse PD severity with increased cardiovascular risk, and underutilization of statins in the PD population [198]. The association of cholesterol and statins as risk factors for PD development has recently been discussed in a Lancet Neurology review by Ascherio \& Schwarzschild [104], which concluded that any possible association remains uncertain. 
Table 1

Key findings from various epidemiological studies that have attempted to determine whether the use of statins is positively or negatively associated with PD risk

\begin{tabular}{llcc}
\hline Reference and Research team & Study Type \& Size & Results & $\begin{array}{c}\text { Statistics and additional } \\
\text { information }\end{array}$ \\
\hline Wolozin et al. [176] & $\begin{array}{c}\text { Retrospective analysis of VA } \\
\text { database of 4.5 million } \\
\text { subjects, which included }\end{array}$ & $\begin{array}{c}\text { Protective. SV 'strongly } \\
\text { protective' of PD risk }\end{array}$ & $\begin{array}{c}\text { SV use reduced the Hazard Ratio } \\
(0.51) p<001\end{array}$
\end{tabular}

Huang et al. [178] 700,000 SV users

Case control study involving 124 PD cases and 112 controls

Wahner et al. [177]

\section{PD cases versus 343} controls. Population-based case control study of incident PD

Becker et al. [179]

Mutez et al. [181]

Gao et al. [183]

Undela et al. [184]

Friedman et al. [185]

Lee et al. [186]

Huang X et al. [188]

Liu et al. [194]
Case-control observational analysis involving 3,637 PD patients ( 378 of whom had or were taking statins), and 3,637 controls

Retrospective analysis of a cohort of 419 PD patients

Prospective study of 129,066 healthy subjects, 644 of whom developed PD over 12 years of follow-up

Meta-analysis, combining 5 case control studies and 3 cohort studies which studied 1.4 million subjects including 15,102 PD cases

94,308 subjects without PD or statin use at baseline. Over 7 years, 1035 developed PD, and 29,714 took statins for at least 6 months

Study followed 43,810 statin users without PD, 1,985 of

Prospective study of 15,792 subjects over 9 years, 106 of whom developed PD while another 187 subjects may have developed PD but this could not be clinically confirmed

Retrospective case control analysis involving 2,322 probable incident PD cases and 2,322 controls. Same research team as 188 whom went on to develop PD
Protective. Use of cholesterol-lowering drugs (primarily statins) in this study group was associated with a lower occurrence of PD

Protective. 3 of 5 different statins were associated with approximately a $55 \%$ reduction in PD risk

No difference found between PD patients and controls

Protective. Mean age of onset of PD delayed 9 years by statin use

Protective. Regular use of statins was associated with a modest reduction in PD risk

Protective. Statin use over a 2-14 year follow-up reduced risk of PD by $23 \%$

Protective. Statin use up to 2.5 years of follow-up in 15,394 patients was associated with a significantly reduced risk of PD

Protective. Use of lipophilic statins, either SV or AV, each reduced the incidence of emergent PD

Disadvantageous. Statin use was associated with a higher risk for PD when adjusted for cholesterol levels

Disadvantageous. Statin usage was significantly associated with PD risk
Odds Ratio $=0.36-0.41$

\author{
Statistically significant Risk
Reduction for SV, AV, LV, but \\ not for PV. Odds Ratios \\ $(p<0.01)$ were $0.38,0.39$ and \\ 0.27 , respectively \\ Odds Ratio $=1.06$
}

Levodopa-equivalent daily dose also reduced in the group taking a statin

Relative Risk was $0.74, p<0.05$, and for subjects under 60 years, Relative Risk was 0.31 , $p=0.02$

Relative Risk $=0.77, p=0.005$

Odds Ratio for reduced risk of $\mathrm{PD}=0.69, p<0.001$

No association noted between baseline LDL-C levels and PD risk

SV and AV significantly reduced the Hazard Ratio (0.23-0.42) for PD risk depending on age and gender. The incidence rate for PD was 1.68 and 3.52 per $1,000,000$ person-days for lipophilic and hydrophilic statins, respectively

Odds Ratio $=2.30, p<0.05$ In addition, higher total cholesterol was associated with lower risk for PD after adjustment for statin use

Strongest associations with PD risk was for lipophilic statins $($ Odds Ratio $=1.58$, $p<0.0001$ ), whereas for hydrophilic statins (Odds Ratio $=1.19, p=0.25)$ 
Table 1

(Continued)

\begin{tabular}{|c|c|c|c|}
\hline Reference and Research team & Study Type \& Size & Results & $\begin{array}{l}\text { Statistics and additional } \\
\text { information }\end{array}$ \\
\hline Rozani et al. [195] & $\begin{array}{l}\text { Population-based cohort of statin } \\
\text { initiators. } 232,877 \text { new statin } \\
\text { users were followed for } 7+ \\
\text { years, and in whom there were } \\
2,550 \text { emergent cases of PD }\end{array}$ & $\begin{array}{l}\text { Statin adherence over time did not } \\
\text { affect PD risk }\end{array}$ & $\begin{array}{l}\text { All-risk estimates were close to } \\
\text { unity (except for a slightly } \\
\text { reduced PD risk: Hazard } \\
\text { Ratio }=0.77 \text { among women } \\
\text { aged } 40-45 \text { with LDL-C level } \\
160 \mathrm{mg} / \mathrm{dl} \text { at baseline) Results } \\
\text { unaffected by whether statins } \\
\text { were lipophilic or hydrophilic }\end{array}$ \\
\hline Bai et al. [189] & $\begin{array}{l}\text { Meta-analysis, combining } 5 \text { case } \\
\text { control studies and } 6 \text { cohort } \\
\text { studies which studied } 3.5 \\
\text { million subjects ( } 1.1 \text { million } \\
\text { statin users), and including } \\
21,011 \text { incident cases of PD }\end{array}$ & $\begin{array}{l}\text { Protective. Statin use was } \\
\text { associated with a reduced risk } \\
\text { of PD }\end{array}$ & $\begin{array}{l}\text { Because of the low incidence of } \\
\text { PD, the authors felt distinctions } \\
\text { among RR, HR, and OR could } \\
\text { be ignored, allowing combined } \\
\text { case-control and cohort studies } \\
\text { and calculated the summary } \\
\text { Relative Risks and } 95 \% \text { CIs. } \\
\text { Relative Risk for reduced PD } \\
\text { risk was } 0.81, p=0.002\end{array}$ \\
\hline Bykov et al. [196] & $\begin{array}{l}\text { Meta-analysis, of ten eligible } \\
\text { epidemiological studies }\end{array}$ & $\begin{array}{l}\text { Protective, but only in the six } \\
\text { studies analyzed that did not } \\
\text { adjust for cholesterol. Protective } \\
\text { effect of statins against PD risk, } \\
\text { Relative Risk }=0.7595 \% \text { CI: } 0.60 \\
\text { to } 0.92\end{array}$ & $\begin{array}{l}\text { No protective effect was observed } \\
\text { among the four studies that } \\
\text { adjusted for either cholesterol } \\
\text { or hyperlipidemia Relative } \\
\text { Risk }=0.91 ; 95 \% \text { CI } 0.68 \text { to } \\
1.22\end{array}$ \\
\hline Sheng et al. [190] & $\begin{array}{l}\text { Meta-analysis, of } 11 \text { studies } \\
(2,787,249 \text { subjects }) \text { including } \\
5 \text { case-control and } 6 \text { cohort } \\
\text { studies }\end{array}$ & $\begin{array}{l}\text { Protective. Use of statins was } \\
\text { associated with a significant } \\
\text { reduction in risk of developing } \\
\text { PD }\end{array}$ & $\begin{array}{l}\text { Adjusted Relative Risk }=0.74 \text {, } \\
95 \% \text { CI } 0.62 \text { to } 0.90, P<0.001\end{array}$ \\
\hline
\end{tabular}

Results, and outcomes measures used, are as described by the respective authors. SV, Simvastatin; AV, Atorvastatin; LV, Lovastatin; PV, Pravastatin.

In conclusion, we reiterate, whether PD risk is increased or decreased by taking a statin to lower cardiovascular risk (and a clear future demonstration of the reality of this would be valuable and welcome), that the testing of a statin to treat PD neurodegeneration in patients who already have established PD is a completely separate and unrelated question. It therefore remains highly reasonable to pursue Simvastatin in a randomized clinical trial to test its diseasemodifying potential in a population of PD patients (see biochemical/pharmaceutical rationale described earlier). In this Simvastatin trial [7] we are measuring PD severity and so will pick up whether or not the rate of PD progression is affected by Simvastatin, hopefully in a positive direction as that is the point of the trial. We are carefully monitoring for adverse events and at the end of the study in 2020 we will finally be able to evaluate the unblinded data.

\section{DESCRIPTION OF CURRENT LCT CLINICAL TRIAL OF SIMVASTATIN}

No drug has yet been shown to slow or reverse the neurodegenerative process of PD. All currently licensed therapies act as symptom-relieving agents but have a limited lifespan of effectiveness because of continued neuronal loss. The purpose of this study, as mandated by the International PD Linked Clinical Trials Committee [6], is to determine whether Simvastatin, a widely used cholesterol-lowering drug (statin) with an excellent safety profile, is capable of reducing the rate of neurodegenerative decline in patients with PD. Details of this clinical trial are described on the US clinical trials website [7]: https:// clinicaltrials.gov/show/NCT02787590.

Briefly, after considerable discussion about how best to configure an appropriate long-term diseasemodifying trial in PD patients (rather than a symptomatic study), a randomized, double-blind, placebo-controlled, two year study was chosen, to be conducted in idiopathic PD patients who, at study commencement, had been characterized as Modified Hoehn and Yahr stage $\leq 3.0$ in the ON medication state. It was made a requirement for entry into the trial that they were on dopaminergic treatment with wearing-off phenomenon.

Participants are randomly allocated to one of two treatment groups. In one group, participants are given 
capsules of Simvastatin to take orally (by mouth) for 24 months.

The other group receives placebo capsules to take orally for 24 months. At the start of the study, when they receive their medication, participants complete a number of questionnaires and motor (movement) tests (a walking test and a finger tapping test). Participants in both groups also attend a further 6 clinic visits after 1, 6, 12, 18 and 24 and 26 months, where they are asked about their health and any medication they are taking, as well as repeating the questionnaires and motor tests. For 4 of the clinic visits, having omitted their usual PD medication that day, the participants are asked to attend in the 'OFF medication' state so that the researchers can get a true picture of their disease without it being masked by their normal medication.

The Simvastatin trial is a 198 patient, 23 Centre, Phase II, randomized, placebo-controlled, doubleblinded study, officially titled 'Simvastatin as a Neuroprotective Treatment for Parkinson's Disease: a Double-blind, Randomised, Placebo Controlled Futility Study in Patients of Moderate Severity'. The primary outcome measure is Change in MDSUPDRS part III (OFF) score, and the duration of treatment is 24 Months. The Secondary Outcome Measures include MDS-UPDRS total score in the practically defined ON state, MDS-UPDRS part II subscale score in the practically defined ON state, Timed motor tests - finger tapping and timed walk test, Timed Motor Tests include evaluating the number of hand taps that an individual can perform within 30 seconds and a timed walk test. In addition, the following rating scales are used to evaluate the study participants: Montgomery and Asberg Depression Rating Scale (MADRS), The Addenbrooke's Cognitive Assessment-III (ACE-III), Non-Motor Symptom assessment scale (NMSS), Parkinson's disease Questionnaire (PDQ-39), Changes in PD medication as measured by levodopa-equivalent dose (LED), Cholesterol levels (total, HDL, total/HDL ratio), King's PD pain scale (KPPS), EuroQoL 5D-5L health status questionnaire (EQ-5D-5L), Safety and tolerability of trial medication by adverse events (AEs) review, and Incidence of diabetes mellitus.

Active comparator: A one month low dose phase of $40 \mathrm{mg}$ oral Simvastatin daily is followed by a 23month high dose phase of $80 \mathrm{mg}$ oral Simvastatin daily and a final two month phase off trial medication. Matched Placebo Comparator: A one month low dose phase of $40 \mathrm{mg}$ matched placebo daily is followed by a 23 month high dose phase of $80 \mathrm{mg}$ matched placebo daily and a final two month phase off trial medication.

\section{Outline of choices made about the Simvastatin trial}

\section{Patient population}

We elected to recruit patients in mid-stage disease, $\mathrm{H} \& \mathrm{Y}<$ or $=3$ in the ON state, but who had developed motor fluctuations. The reason for this was two-fold. First, we felt that the trial findings would be of relevance to people living with PD today. Second, the presence of wearing off reduces the degree of heterogeneity in the study population, particularly for ensuring, as much as possible, consistency in the 'practically-defined off' state used for the primary outcome measure.

\section{Study sites}

We selected a multi-center design as it would not be possible to recruit the required number of participants from a single center. Within the UK we have an established Clinical Research Network that facilitates study delivery within centers experienced in PD clinical study delivery. The multi-center nature of the study does introduce issues relating to quality control, particularly with regard to rater experience and training. We therefore carried out feasibility assessments with sites expressing interest, stipulating the study requirements in terms of rater uniformity for the study duration, the need for an independent rater (separate from the rest of study delivery), rater experience and training (kindly provided by the MDS for this study). In addition, the study co-ordinating center has robust data management and site monitoring processes to ensure quality data collection across all sites.

\section{Dose of Simvastatin chosen}

We chose to use a dose of $80 \mathrm{mg}$ of Simvastatin for this study, as this was the dose shown to have an excellent protective effect in the MS STAT trial involving treating Multiple Sclerosis patients [135, 199]. There are safety concerns regarding the use of high dose Simvastatin, particularly in the elderly. The overall risk of statin-induced myopathy is approximately $1 \%$. We have introduced robust guidance and safety procedures into the protocol to mitigate this risk.

\section{Choice of selected duration of clinical trial}

Study duration was chosen as 24 months to maximize the potential for differences in progression 
between placebo and active treatment group. It is known that the placebo effect in PD studies is large and sustained. In addition, with a relatively small sample size and a clinically heterogeneous condition, it is important to allow sufficient time for measurable disease progression across the study population.

\section{Choice of primary patient outcome}

Choice of primary outcome measure was the OFF state MDS-UPDRS part III as this is the most likely to correlate with underlying disease severity and therefore be indicative of disease progression. This does not reflect clinical meaningfulness for patients whose OFF state UPDRS score will be improved by symptomatic medication; however, demonstrating clinical utility is not the purpose of this preliminary study. If this study suggests that Simvastatin does have potential as a neuroprotective agent, then a further Phase III study can evaluate impact on clinically meaningful outcomes, such as patient reported measures, quality of life measures, and cognitive decline.

\section{Other design aspects}

In order to distinguish a protective effect from a potential symptomatic effect a washout design was chosen with a 2-month washout period after the end of the 24-month treatment period. The half-life of Simvastatin is less than 5 hours, and so this period provides sufficient time for drug elimination.

\section{DISCUSSION}

The international PD linked clinical trials committee, based on a range of evidence compiled into a detailed dossier, and followed by extensive committee discussions, agreed in 2012 to prioritize Simvastatin to enter a trial in PD patients to assess its potential as a disease-modifying therapy [6]. Clinical trials of potential neuroprotective agents in PD are difficult to design. This is partially because of the variability in disease phenotype and rate of progression, and also, the potential confounding factor of a symptomatic response. In addition, there is no reliable biomarker for disease progression. The International PD Linked Clinical Trial committee is tasked to analyze potential new target therapies for PD and for which the biochemical evidence indicates the likelihood that they may have benefit to slow, halt or reverse disease progression in patients with PD. This large global committee of PD experts, many of whom have extensive experience in PD trials and their design, is coordinated by The Cure Parkinson's
Trust. The detailed biochemical, physiological, and pharmaceutical evidence available to the committee in 2012 which led them to choose to prioritize Simvastatin to enter a disease-modifying clinical trial is summarized in the first section of the current paper, with very substantial updating to October 2017. It is interesting to observe that the rationale, then in 2012, for taking Simvastatin into a PD trial to assess its disease-modifying potential (in fact, there are several separate mechanistic rationales as outlined above) has continued to strengthen over those 5 years on all biochemical and physiological fronts. Another recent review by Saeedi Saravi et al. [200] also summarizes, but more generally across several neurodegenerative diseases, the biochemical and pharmaceutical mechanisms of action of how statins may be beneficial in the management of these conditions. In their discussion of the treatment of multiple sclerosis they explore research into how immunomodulatory and anti-inflammatory properties of statins may helpfully unite for therapeutic benefit [201-203] and this may also be of direct relevance to the longterm management of PD. This is especially poignant since Simvastatin has already shown encouraging long-term clinical results in patients with multiple sclerosis [135, 199, 204], and a major Phase III study involving almost 1200 patients being given high dose Simvastatin ( $80 \mathrm{mg}$ daily) will commence in the coming months. We have long established strong lines of communication between those involved with the multiple sclerosis (MS-STAT) and Simvastatin (PD STAT) trials.

Taking the example, also conceptually relevant to PD, of the costs of some of the newer multiple sclerosis (patented) therapeutics that are pursuing disease-modification objectives, several of these currently exceed $\$ 75,000$ per patient per year [205]. By contrast, the annual cost per patient of $80 \mathrm{mg}$ Simvastatin (now unpatented) is $\$ 37$ per year [206], although that is not to say that the cost effectiveness of those high value therapies render them financially unusable [207-209], as this can vary across patient subgroups which in turn means that direct therapeutic, or even financial, comparisons with Simvastatin cannot always readily be made. However, there may be situations in the future where low cost unpatented drugs like Simvastatin may look a very attractive therapeutic alternative for healthcare providers, while the patient perspective can be somewhat different and must also be taken in to account [210] because health economic algorithms currently used often miss substantial additional social value. 
The first, biochemical, section of this paper demonstrates that Simvastatin acts on a number of separate, distinct intracellular processes, each of which appear of relevance to the long-term management of PD. These remain highly active research topics and we eagerly anticipate developments into this growing insight. When a repurposed therapeutic such as Simvastatin, has multiple pleiotropic effects, all or any of which may be clinically beneficial, there sometimes comes a point when one may just acknowledge we cannot identify a clear therapeutic target (because there are so many positively-orientated candidate modes of action), and go ahead and test it in the clinic. To quote John Overington from BenevolentAI, 'although the concept of a single drug target is a natural one for researchers in the field, there are substantial operational difficulties in consistently mapping this target concept to specific genes and gene products' [211]. Clearly, having a strong and extensive safety record has helped us move Simvastatin into a long-term trial in PD patients to explore its diseasemodifying potential. We anticipate our current Simvastatin trial in PD patients will finish in 2020.

\section{ACKNOWLEDGMENTS}

This work is supported by the Cure Parkinson's Trust and the J P Moulton Charitable Foundation.

\section{CONFLICTS OF INTEREST}

CC is the chief investigator of PD STAT, a clinical trial exploring Simvastatin as a neuroprotective treatment for patients with Parkinson's disease. She has no other conflicts of interest relevant to this publication.

RW is the Director of Research and Development at the Cure Parkinson's Trust which is an international grant-giving charity focused on delivering fundamentally innovative disease-modifying treatments that slow, stop or reverse Parkinson's disease. He declares no conflicts of interest relevant to this publication.

\section{REFERENCES}

[1] Hirsch L, Jette N, Frolkis A, Steeves T, \& Pringsheim $\mathrm{T}$ (2016) The incidence of Parkinson's disease: A systematic review and meta-analysis. Neuroepidemiology, 46, 292-300.

[2] Dorsey ER, Constantinescu R, Thompson JP, Biglan KM, Holloway RG, Kieburtz K, Marshall FJ, Ravina BM, Schifitto G, Siderowf A, \& Tanner CM (2007) Projected number of people with Parkinson disease in the most populous nations, 2005 through 2030. Neurology, 30, 384-386.
[3] Kowal SL, Dall TM, Chakrabarti R, Storm MV, \& Jain A (2013) The current and projected economic burden of Parkinson's disease in the United States. Mov Disord, 28, 311-318.

[4] Savica R, Grossardt BR, Bower JH, Ahlskog JE, \& Rocca WA (2016) Time Trends in the Incidence of Parkinson Disease. JAMA Neurol, 73, 981-989.

[5] Johnson SJ, Diener MD, Kaltenboeck A, Birnbaum HG, \& Siderowf AD (2013) An economic model of Parkinson's disease: Implications for slowing progression in the United States. Mov Disord, 28, 319-326.

[6] Brundin P, Barker RA, Conn PJ, Dawson TM, Kieburtz $\mathrm{K}$, Lees AJ, Schwarzschild MA, Tanner CM, Isaacs T, Duffen J, Matthews H, \& Wyse RK (2013) Linked clinical trials-the development of new clinical learning studies in Parkinson's disease using screening of multiple prospective new treatments. J Parkinsons Dis, 3, 231-239.

[7] Simvastatin as a Neuroprotective Treatment for Moderate Parkinson's Disease (PD STAT) https://clini caltrials.gov/ct2/show/NCT02787590 Last verified April 2017. Accessed on October, 1, 2017.

[8] Vuletic S, Riekse RG, Marcovina SM, Peskind ER, Hazzard WR, \& Albers JJ (2006) Statins of different brain penetrability differentially affect CSF PLTP activity. Dement Geriatr Cogn Disord 22, 392-398.

[9] Wood WG, Eckert GP, Igbavboa U, \& Müller WE (2010) Statins and neuroprotection: A prescription to move the field forward. Ann N Y Acad Sci, 1199, 69-76.

[10] Wood WG, Müller WE, \& Eckert GP (2014) Statins and neuroprotection: Basic pharmacology needed. $\mathrm{Mol} \mathrm{Neu}$ robiol, 50, 214-220.

[11] Selley ML (2005) Simvastatin prevents 1-methyl4-phenyl-1,2,3,6-tetrahydropyridine-induced striatal dopamine depletion and protein tyrosine nitration in mice. Brain Res, 1037, 1-6.

[12] Ghosh A, Roy A, Matras J, Brahmachari S, Gendelman HE, \& Pahan K (2009) Simvastatin inhibits the activation of p21ras and prevents the loss of dopaminergic neurons in a mouse model of Parkinson's disease. J Neurosci, 43, 13543-13556.

[13] Roy A, \& Pahan K (2011) Prospects of statins in Parkinson disease. Neuroscientist, 17, 244-255.

[14] Hunot S, Boissière F, Faucheux B, Brugg B, MouattPrigent A, Agid Y, \& Hirsch EC (1996) Nitric oxide synthase and neuronal vulnerability in Parkinson's disease. Neuroscience, 72, 355-363.

[15] Qureshi GA, Baig S, Bednar I, Södersten P, Forsberg G, \& Siden A (1995) Increased cerebrospinal fluid concentration of nitrite in Parkinson's disease. Neuroreport, 6 , 1642-1644.

[16] Bessler H, Djaldetti R, Salman H, Bergman M, \& Djaldetti M (1999) IL-1 beta, IL-2, IL-6 and TNF-alpha production by peripheral blood mononuclear cells from patients with Parkinson's disease. Biomed Pharmacother, 53, 141-145.

[17] Dehmer T, Lindenau J, Haid S, Dichgans J, \& Schulz JB (2000) Deficiency of inducible nitric oxide synthase protects against MPTP toxicity in vivo. J Neurochem, $\mathbf{7 4 ,}$ 2213-2216.

[18] Sriram K, Matheson JM, Benkovic SA, Miller DB, Luster MI, \& O'Callaghan JP (2006) Deficiency of TNF receptors suppresses microglial activation and alters the susceptibility of brain regions to MPTP-induced neurotoxicity: role of TNF-alpha. FASEB J, 20, 670-682. 
[19] Ghosh A, Roy A, Liu X, Kordower JH, Mufson EJ, Hartley DM, Ghosh S, Mosley RL, Gendelman HE, \& Pahan K (2007) Selective inhibition of NF-kappaB activation prevents dopaminergic neuronal loss in a mouse model of Parkinson's disease. Proc Natl Acad Sci USA, 104, 18754 18759.

[20] Saijo K, Winner B, Carson CT, Collier JG, Boyer L, Rosenfeld MG, Gage FH, \& Glass CK (2009) A Nurr1/CoREST pathway in microglia and astrocytes protects dopaminergic neurons from inflammation-induced death. Cell, 137, 47-59.

[21] Pahan K, Sheikh FG, Namboodiri AM, \& Singh I (1997) Lovastatin and phenylacetate inhibit the induction of nitric oxide synthase and cytokines in rat primary astrocytes, microglia, and macrophages. J Clin Invest, 100, 26712679.

[22] Stanislaus R, Singh AK, \& Singh I (2001) Lovastatin treatment decreases mononuclear cell infiltration into the CNS of Lewis rats with experimental allergic encephalomyelitis. J Neurosci Res, 66, 155-162.

[23] Neuhaus O, Strasser-Fuchs S, Fazekas F, Kieseier BC, Niederwieser G, Hartung HP, \& Archelos JJ (2002) Statins as immunomodulators: comparison with interferon-beta 1b in MS. Neurology, 59, 990-997.

[24] Clarke RM, Lyons A, O'Connell F, Deighan BF, Barry CE, Anyakoha NG, Nicolaou A, \& Lynch MA (2008) A pivotal role for interleukin-4 in atorvastatin-associated neuroprotection in rat brain. J Biol Chem, 283, 1808-1817.

[25] Pahan K, Liu X, McKinney MJ, Wood C, Sheikh FG, \& Raymond JR (2000) Expression of a dominant-negative mutant of p21(ras) inhibits induction of nitric oxide synthase and activation of nuclear factor-kappaB in primary astrocytes. J Neurochem, 74, 2288-2295.

[26] Pahan K, Sheikh FG, Khan M, Namboodiri AM, \& Singh I (1998) Sphingomyelinase and ceramide stimulate the expression of inducible nitric-oxide synthase in rat primary astrocytes. J Biol Chem, 273, 2591-2600.

[27] van der Most PJ, Dolga AM, Nijholt IM, Luiten PG, \& Eisel UL (2009) Statins: mechanisms of neuroprotection. Prog Neurobiol, 88, 64-75.

[28] Santiago M, Hernández-Romero MC, Machado A, \& Cano J (2009) Zocor Forte (simvastatin) has a neuroprotective effect against LPS striatal dopaminergic terminals injury, whereas against MPP+ does not. Eur J Pharmacol, 609, 58-64.

[29] Liu TY, Yang XY, Zheng LT, Wang GH, \& Zhen XC (2017) Activation of Nur77 in microglia attenuates proinflammatory mediators production and protects dopaminergic neurons from inflammation-induced cell death. $\mathrm{J} \mathrm{Neu}$ rochem, 140, 589-604.

[30] Gouveia TL, Scorza FA, Silva MJ, Bandeira Tde A, Perosa SR, Argañaraz GA, Silva Mde P, Araujo TR, Frangiotti MI, Amado D, Cavalheiro EA, Silva JA Jr, \& NaffahMazzacoratti Mda G (2011) Lovastatin decreases the synthesis of inflammatory mediators in the hippocampus and blocks the hyperthermia of rats submitted to longlasting status epilepticus. Epilepsy Behav, 20, 1-5.

[31] Kurata T, Miyazaki K, Kozuki M, Morimoto N, Ohta Y, Ikeda Y, \& Abe K (2012) Atorvastatin and pitavastatin reduce senile plaques and inflammatory responses in a mouse model of Alzheimer's disease. Neurol Res, 34, 601-610.

[32] Tong XK, Nicolakakis N, Fernandes P, Ongali B, Brouillette J, Quirion R, \& Hamel E (2009) Simvastatin improves cerebrovascular function and counters soluble amyloid- beta, inflammation and oxidative stress in aged APP mice. Neurobiol Dis, 35, 406-414.

[33] Zhao Y, Feng Q, Huang Z, Li W, Chen B, Jiang L, Wu B, Ding W, Xu G, Pan H, Wei W, Luo W, \& Luo Q (2014) Simvastatin inhibits inflammation in ischemia-reperfusion injury. Inflammation, 37, 1865-1875.

[34] Ouk T, Amr G, Azzaoui R, Delassus L, Fossaert E, Tailleux A, Bordet R, \& Modine T (2016) Lipid-lowering drugs prevent neurovascular and cognitive consequences of cardiopulmonary bypass. Vascul Pharmacol, 80, 59-66.

[35] Yan J, Xu Y, Zhu C, Zhang L, Wu A, Yang Y, Xiong Z, Deng C, Huang XF, Yenari MA, Yang YG, Ying W, \& Wang Q (2011) Simvastatin prevents dopaminergic neurodegeneration in experimental parkinsonian models: the association with anti-inflammatory responses. PLoS One, 6, e20945.

[36] Kumar A, Sharma N, Gupta A, Kalonia H, \& Mishra J (2012) Neuroprotective potential of atorvastatin and simvastatin (HMG-CoA reductase inhibitors) against 6-hydroxydopamine (6-OHDA) induced Parkinson-like symptoms. Brain Res, 1471, 13-22.

[37] Esposito E, Rinaldi B, Mazzon E, Donniacuo M, Impellizzeri D, Paterniti I, Capuano A, Bramanti P, \& Cuzzocrea S (2012) Anti-inflammatory effect of simvastatin in an experimental model of spinal cord trauma: involvement of PPAR- $\alpha$. J Neuroinflammation, $\mathbf{9}, 81$.

[38] Rinaldi B, Donniacuo M, Esposito E, Capuano A, Sodano L, Mazzon E, Di Palma D, Paterniti I, Cuzzocrea S, \& Rossi F (2011) PPAR $\alpha$ mediates the anti-inflammatory effect of simvastatin in an experimental model of zymosan-induced multiple organ failure. Br J Pharmacol, 163, 609-623.

[39] Zhou HX, Gao LH, Meng LL, Zhang YX, Wei ZF, \& Si DW (2017) Preventive and therapeutic effect of simvastatin on secondary inflammatory damage of rats with cerebral hemorrhage. Asian Pac J Trop Med, 10, 152-156.

[40] Xu YQ, Long L, Yan JQ, Wei L, Pan MQ, Gao HM, Zhou P, Liu M, Zhu CS, Tang BS, \& Wang Q (2013) Simvastatin induces neuroprotection in 6-OHDA-lesioned $\mathrm{PC} 12$ via the PI3K/AKT/caspase 3 pathway and anti-inflammatory responses. CNS Neurosci Ther, 19, 170-177.

[41] Yan J, Sun J, Huang L, Fu Q, \& Du G (2014) Simvastatin prevents neuroinflammation by inhibiting N-methyl-Daspartic acid receptor 1 in 6-hydroxydopamine-treated PC12 cells. J Neurosci Res, 92, 634-640.

[42] Zhang Y, Zhang Z, \& Yan H (2015) Simvastatin inhibits ischemia/reperfusion injury-induced apoptosis of retinal cells via downregulation of the tumor necrosis factor$\alpha /$ nuclear factor- $\kappa \mathrm{B}$ pathway. Int J Mol Med, 36, 399-405.

[43] Tran TA, Nguyen AD, Chang J, Goldberg MS, Lee JK, \& Tansey MG (2011) Lipopolysaccharide and tumor necrosis factor regulate Parkin expression via nuclear factor-kappa B. PLoS One, 6, e23660.

[44] Huang W, Li Z, Zhao L, \& Zhao W (2017) Simvastatin ameliorate memory deficits and inflammation in clinical and mouse model of Alzheimer's disease via modulating the expression of miR-106b. Biomed Pharmacother, 92, 46-57.

[45] Wang Q, Wei X, Gao H, Li J, Liao J, Liu X, Qin B, Yu Y, Deng C, Tang B, \& Huang XF (2014) Simvastatin reverses the downregulation of M1/4 receptor binding in 6-hydroxydopamine-induced parkinsonian rats: the association with improvements in long-term memory. Neuroscience, 267, 57-66. 
[46] Beal MF (1998) Excitotoxicity and nitric oxide in Parkinson's disease pathogenesis. Ann Neurol 44(3 Suppl 1), S110-S114.

[47] Hernández-Perera O, Pérez-Sala D, Navarro-Antolín J, Sánchez-Pascuala R, Hernández G, Díaz C, \& Lamas S (1998) Effects of the 3-hydroxy-3-methylglutaryl-CoA reductase inhibitors, atorvastatin and simvastatin, on the expression of endothelin-1 and endothelial nitric oxide synthase in vascular endothelial cells. J Clin Invest, 101, 2711-2719.

[48] Fulton D, Gratton JP, McCabe TJ, Fontana J, Fujio Y, Walsh K, Franke TF, Papapetropoulos A, \& Sessa WC (1999) Regulation of endothelium-derived nitric oxide production by the protein kinase Akt. Nature, 399, 597-601.

[49] Skaletz-Rorowski A, Lutchman M, Kureishi Y, Lefer DJ, Faust JR, \& Walsh K (2003) HMG-CoA reductase inhibitors promote cholesterol-dependent Akt/PKB translocation to membrane domains in endothelial cells. Cardiovasc Res, 57, 253-264.

[50] Feron O, Dessy C, Desager JP, \& Balligand JL (2001) Hydroxy-methylglutaryl-coenzyme A reductase inhibition promotes endothelial nitric oxide synthase activation through a decrease in caveolin abundance. Circulation, 103, 113-118.

[51] Arora R, Hare DL, \& Zulli A (2012) Simvastatin reduces endothelial NOS: Caveolin-1 ratio but not the phosphorylation status of eNOS in vivo. J Atheroscler Thromb, 19, 705-711.

[52] Pugh SD, MacDougall DA, Agarwal SR, Harvey RD, Porter KE, \& Calaghan S (2014) Caveolin contributes to the modulation of basal and $\beta$-adrenoceptor stimulated function of the adult rat ventricular myocyte by simvastatin: a novel pleiotropic effect. PLoS One, 9, e106905.

[53] Chang CC, Hsu YH, Chou HC, Lee YG, \& Juan SH (2017) 3-methylcholanthrene/aryl-hydrocarbon receptormediated hypertension through eNOS inactivation. J Cell Physiol, 232, 1020-1029.

[54] Saeedi Saravi SS, Saeedi Saravi SS, Khoshbin K, \& Dehpour AR (2017) Current insights into pathogenesis of Parkinson's disease: Approach to mevalonate pathway and protective role of statins. Biomed Pharmacother, 90, 724-730.

[55] Schmitt M, Dehay B, Bezard E, \& Garcia-Ladona FJ (2016) Harnessing the trophic and modulatory potential of statins in a dopaminergic cell line. Synapse, 70, 71-86.

[56] Schmitt M, Dehay B, Bezard E, \& Garcia-Ladona FJ (2017) U18666A, an activator of sterol regulatory element binding protein pathway, modulates presynaptic dopaminergic phenotype of SH-SY5Y neuroblastoma cells. Synapse 71. doi: 10.1002/syn.21980

[57] Miyosawa K, Watanabe Y, Murakami K, Murakami T, Shibata $\mathrm{H}$, Iwashita M, Yamazaki H, Yamazaki K, Ohgiya T, Shibuya K, Mizuno K, Tanabe S, Singh SA, \& Aikawa M (2015) New CETP inhibitor K-312 reduces PCSK9 expression: a potential effect on LDL cholesterol metabolism. Am J Physiol Endocrinol Metab, 309, E177-E190.

[58] Ferri N, Marchianò S, Lupo MG, Trenti A, Biondo G, Castaldello P, \& Corsini A (2017) Geranylgeraniol prevents the simvastatin-induced PCSK9 expression: Role of the small G protein Rac1. Pharmacol Res, 122, 96-104.

[59] Benn M, Nordestgaard BG, Frikke-Schmidt R, \& TybjærgHansen A (2017) Low LDL cholesterol, PCSK9 and HMGCR genetic variation, and risk of Alzheimer's disease and Parkinson's disease: Mendelian randomisation study. BMJ, 357, $\mathrm{j} 3170$.

[60] Chaudhary R, Garg J, Shah N, \& Sumner A (2017) PCSK9 inhibitors: A new era of lipid lowering therapy. World $J$ Cardiol, 9, 76-91.

[61] Scherer DJ, Nelson A, Psaltis PJ, \& Nicholls SJ (2017) Targeting LDL cholesterol with PCSK9 inhibitors. Intern Med J, 47, 856-865.

[62] Jaworski K, Jankowski P, \& Kosior DA (2017) PCSK9 inhibitors - from discovery of a single mutation to a groundbreaking therapy of lipid disorders in one decade. Arch Med Sci, 13, 914-929.

[63] Berthold HK, Seidah NG, Benjannet S, \& Gouni-Berthold I (2013) Evidence from a randomized trial that simvastatin, but not ezetimibe, upregulates circulating PCSK9 levels. PLoS One, 8, e60095.

[64] Sun HX, Zeng DY, Li RT, Pang RP, Yang H, Hu YL, Zhang Q, Jiang Y, Huang LY, Tang YB, Yan GJ, \& Zhou JG (2012) Essential role of microRNA-155 in regulating endothelium-dependent vasorelaxation by targeting endothelial nitric oxide synthase. Hypertension, 60, 14071414.

[65] Pierucci M, Galati S, Valentino M, Di Matteo V, Benigno A, Pitruzzella A, Muscat R, \& Di Giovanni G (2011) Nitric oxide modulation of the basal ganglia circuitry: therapeutic implication for Parkinson's disease and other motor disorders. CNS Neurol Disord Drug Targets, 10, 777-791.

[66] Hoang T, Choi DK, Nagai M, Wu DC, Nagata T, Prou D, Wilson GL, Vila M, Jackson-Lewis V, Dawson VL, Dawson TM, Chesselet MF, \& Przedborski S (2009) Neuronal NOS and cyclooxygenase- 2 contribute to DNA damage in a mouse model of Parkinson disease. Free Radic Biol Med, 47, 1049-1056.

[67] Brzozowski MJ, Jenner P, \& Rose S (2015) Inhibition of i-NOS but not n-NOS protects rat primary cell cultures against MPP(+)-induced neuronal toxicity. J Neural Transm (Vienna), 122, 779-788.

[68] Tripathy D, Chakraborty J, \& Mohanakumar KP (2015) Antagonistic pleiotropic effects of nitric oxide in the pathophysiology of Parkinson's disease. Free Radic Res, 49, 1129-1139.

[69] Jiménez-Jiménez FJ, Alonso-Navarro H, Herrero MT, García-Martín E, \& Agúndez JA (2016) An update on the role of nitric oxide in the neurodegenerative processes of Parkinson's disease. Curr Med Chem, 23, 2666-2679.

[70] Li WC, Zou ZJ, Zhou MG, Chen L, Zhou L, Zheng YK, \& He ZJ (2015) Effects of simvastatin on the expression of inducible NOS in acute lung injury in septic rats. Int $J$ Clin Exp Pathol, 8, 15106-15111.

[71] Padovan-Neto FE, Echeverry MB, Chiavegatto S, \& DelBel E (2011) Nitric Oxide Synthase Inhibitor Improves De Novo and Long-Term 1-DOPA-Induced Dyskinesia in Hemiparkinsonian Rats. Front Syst Neurosci, 5, 40.

[72] Padovan-Neto FE, Cavalcanti-Kiwiatkoviski R, Carolino RO, Anselmo-Franci J, \& Del Bel E (2015) Effects of prolonged neuronal nitric oxide synthase inhibition on the development and expression of L-DOPA-induced dyskinesia in 6-OHDA-lesioned rats. Neuropharmacology, 89, 87-99.

[73] Solís O, Espadas I, Del-Bel EA, \& Moratalla R (2015) Nitric oxide synthase inhibition decreases 1-DOPAinduced dyskinesia and the expression of striatal molecular markers in Pitx3(-/-) aphakia mice. Neurobiol Dis, 73, 49-59. 
[74] Bortolanza M, Cavalcanti-Kiwiatkoski R, Padovan-Neto FE, da-Silva CA, Mitkovski M, Raisman-Vozari R, \& DelBel E (2015) Glial activation is associated with 1-DOPA induced dyskinesia and blocked by a nitric oxide synthase inhibitor in a rat model of Parkinson's disease. Neurobiol Dis, 73, 377-387.

[75] Gerfen CR, Miyachi S, Paletzki R, \& Brown P (2002) D1 dopamine receptor supersensitivity in the dopaminedepleted striatum results from a switch in the regulation of ERK1/2/MAP kinase. J Neurosci, 22, 5042-5054.

[76] Westin JE, Vercammen L, Strome EM, Konradi C, \& Cenci MA (2007) Spatiotemporal pattern of striatal ERK1/2 phosphorylation in a rat model of L-DOPA-induced dyskinesia and the role of dopamine D1 receptors. Biol Psychiatry, 62, 800-810.

[77] Schuster S, Nadjar A, Guo JT, Li Q, Ittrich C, Hengerer B, \& Bezard E (2008) The 3-hydroxy-3-methylglutaryl-CoA reductase inhibitor lovastatin reduces severity of L-DOPAinduced abnormal involuntary movements in experimental Parkinson's disease. J Neurosci, 28, 4311-4316.

[78] Tison F, Nègre-Pagès L, Meissner WG, Dupouy S, Li Q, Thiolat ML, Thiollier T, Galitzky M, Ory-Magne F, Milhet A, Marquine L, Spampinato U, Rascol O, \& Bezard E (2013) Simvastatin decreases levodopa-induced dyskinesia in monkeys, but not in a randomized, placebocontrolled, multiple cross-over ("n-of-1") exploratory trial of simvastatin against levodopa-induced dyskinesia in Parkinson's disease patients. Parkinsonism Relat Disord, 19, 416-421.

[79] Wu DC, Teismann P, Tieu K, Vila M, Jackson-Lewis V, Ischiropoulos H, \& Przedborski S (2003) NADPH oxidase mediates oxidative stress in the 1-methyl-4phenyl-1,2,3,6-tetrahydropyridine model of Parkinson's disease. Proc Natl Acad Sci USA, 100, 6145-6150.

[80] Gao HM, Liu B, Zhang W, \& Hong JS (2003) Critical role of microglial NADPH oxidase-derived free radicals in the in vitro MPTP model of Parkinson's disease. FASEB J, 17, 1954-1956.

[81] Sykiotis GP, \& Bohmann D (2010) Stress-activated cap'n' collar transcription factors in aging and human disease. Sci Signal, 3, re3.

[82] Lacher SE, Lee JS, Wang X, Campbell MR, Bell DA, \& Slattery M (2015) Beyond antioxidant genes in the ancient $\mathrm{Nrf} 2$ regulatory network. Free Radic Biol Med $\mathbf{8 8}(\mathrm{Pt} \mathrm{B})$, 452-465.

[83] Lacher SE, \& Slattery M (2016) Gene regulatory effects of disease-associated variation in the NRF2 network. Curr Opin Toxicol, 1, 71-79.

[84] Liu X, Ward K, Xavier C, Jann J, Clark AF, Pang IH, \& Wu H (2016) The novel triterpenoid RTA 408 protects human retinal pigment epithelial cells against $\mathrm{H} 2 \mathrm{O} 2$-induced cell injury via NF-E2-related factor 2 (Nrf2) activation. Redox Biol, 8, 98-109.

[85] Probst BL, Trevino I, McCauley L, Bumeister R, Dulubova I, Wigley WC, \& Ferguson DA (2015) RTA 408, A Novel Synthetic Triterpenoid with Broad Anticancer and AntiInflammatory Activity. PLoS One, 10, e0122942.

[86] Cho HY, Kim K, Kim YB, Kim H, \& No JH (2017) Expression patterns of Nrf2 and Keap1 in ovarian cancer cells and their prognostic role in disease recurrence and patient survival. Int J Gynecol Cancer, 27, 412-419.

[87] Lu J, Guo S, Xue X, Chen Q1 Ge J, Zhuo Y, Zhong H, Chen B, Zhao M, Han W, Suzuki T, Zhu M, Xia L, Schneider C, Blackwell TS, Porter NA, Zheng L, Tsimikas S, \& Yin H (2017) Identification of a novel series of anti- inflammatory and anti-oxidative phospholipid oxidation products containing cyclopentenone moiety in vitro and in vivo: Implication in atherosclerosis. J Biol Chem, 292, 5378-5391.

[88] Sharma A, Rizky L, Stefanovic N, Tate M, Ritchie RH, Ward KW, \& de Haan JB (2017) The nuclear factor (erythroid-derived 2)-like 2 (Nrf2) activator dh404 protects against diabetes-induced endothelial dysfunction. Cardiovasc Diabetol, 16, 33.

[89] Lin CP, Huang PH, Lai CF, Chen JW, Lin SJ, \& Chen JS (2015) Simvastatin attenuates oxidative stress, NF- $\kappa$ B activation, and artery calcification in LDLR-/- mice fed with high fat diet via down-regulation of tumor necrosis factor- $\alpha$ and TNF receptor 1. PLoS One, 10, e0143686.

[90] Sohn HM, Hwang JY, Ryu JH, Kim J, Park S, Park JW, \& Han SH (2017) Simvastatin protects ischemic spinal cord injury from cell death and cytotoxicity through decreasing oxidative stress: in vitro primary cultured rat spinal cord model under oxygen and glucose deprivationreoxygenation conditions. J Orthop Surg Res, 12, 36.

[91] Nakagami Y, \& Masuda K (2016) A novel Nrf2 activator from microbial transformation inhibits radiation-induced dermatitis in mice. J Radiat Res, 57, 567-571.

[92] Gan L, \& Johnson JA (2014) Oxidative damage and the Nrf2-ARE pathway in neurodegenerative diseases. Biochim Biophys Acta, 1842, 1208-1218.

[93] Holmström KM, Kostov RV, \& Dinkova-Kostova AT (2016) The multifaceted role of Nrf2 in mitochondrial function. Curr Opin Toxicol, 1, 80-91.

[94] Dinkova-Kostova AT, Baird L, Holmström KM, Meyer CJ, \& Abramov AY (2015) The spatiotemporal regulation of the Keap1-Nrf2 pathway and its importance in cellular bioenergetics. Biochem Soc Trans, 43, 602-610.

[95] Dinkova-Kostova AT, Holtzclaw WD, Cole RN, Itoh K, Wakabayashi N, Katoh Y, Yamamoto M, \& Talalay P (2002) Direct evidence that sulfhydryl groups of Keap1 are the sensors regulating induction of phase 2 enzymes that protect against carcinogens and oxidants. Proc Natl Acad Sci USA, 99, 11908-11913.

[96] McMahon M, Itoh K, Yamamoto M, \& Hayes JD (2003) Keap1-dependent proteasomal degradation of transcription factor Nrf2 contributes to the negative regulation of antioxidant response element-driven gene expression. J Biol Chem, 278, 21592-21600.

[97] Wang X, Campbell MR, Lacher SE, Cho HY, Wan M, Crowl CL, Chorley BN, Bond GL, Kleeberger SR, Slattery M, \& Bell DA (2016) A polymorphic antioxidant response element links NRF2/sMAF binding to enhanced MAPT expression and reduced risk of parkinsonian disorders. Cell Rep. pii: S2211-1247(16)30357-6.

[98] Vandrovcova J, Pittman AM, Malzer E, Abou-Sleiman PM, Lees AJ, Wood NW, \& de Silva R. (2009) Association of MAPT haplotype-tagging SNPs with sporadic Parkinson's disease. Neurobiol Aging, 30, 1477-1482.

[99] Edwards TL, Scott WK, Almonte C, Burt A, Powell EH, Beecham GW, Wang L, Züchner S, Konidari I, Wang G, Singer C, Nahab F, Scott B, Stajich JM, Pericak-Vance M, Haines J, Vance JM, \& Martin ER (2010) Genome-wide association study confirms SNPs in SNCA and the MAPT region as common risk factors for Parkinson disease. Ann Hum Genet, 74, 97-109.

[100] Kumaran R, \& Cookson MR (2015) Pathways to Parkinsonism Redux: convergent pathobiological mechanisms in genetics of Parkinson's disease. Hum Mol Genet 24(R1), R32-44. 
[101] Ahuja M, Ammal Kaidery N, Yang L, Calingasan N, Smirnova N, Gaisin A, Gaisina IN, Gazaryan I, Hushpulian DM, Kaddour-Djebbar I, Bollag WB, Morgan JC, Ratan RR, Starkov AA, Beal MF, \& Thomas B (2016) Distinct Nrf2 signaling mechanisms of fumaric acid esters and their role in neuroprotection against 1-methyl-4phenyl-1,2,3,6-tetrahydropyridine-induced experimental Parkinson's-like disease. Neuroscience, 36, 6332-6351.

[102] Campolo M, Casili G, Biundo F, Crupi R, Cordaro M, Cuzzocrea S, \& Esposito E (2017) The neuroprotective effect of dimethyl fumarate in an MPTP-mouse model of Parkinson's disease: Involvement of reactive oxygen species/nuclear factor- $\kappa \mathrm{B} /$ nuclear transcription factor related to NF-E2. Antioxid Redox Signal, 27, 453-471.

[103] Abdelsalam RM, \& Safar MM (2015) Neuroprotective effects of vildagliptin in rat rotenone Parkinson's disease model: Role of RAGE-NF $\kappa \mathrm{B}$ and Nrf2-antioxidant signaling pathways. J Neurochem, 133, 700-707.

[104] Ascherio A, \& Schwarzschild MA (2016) The epidemiology of Parkinson's disease: Risk factors and prevention. Lancet Neurol, 15, 1257-1272.

[105] Study of Urate Elevation in Parkinson's Disease, Phase 3 (SURE-PD3) https://clinicaltrials.gov/show/NCT0264 2393 Verified June 28 2017. Accessed October 12017.

[106] Abdanipour A, Tiraihi T, Noori-Zadeh A, Majdi A, \& Gosaili R (2014) Evaluation of lovastatin effects on expression of anti-apoptotic Nrf 2 and PGC- $1 \alpha$ genes in neural stem cells treated with hydrogen peroxide. $\mathrm{Mol}$ Neurobiol, 49, 1364-1372.

[107] Wu W, Zhao L, Yang P, Zhou W, Li B, Moorhead JF, Varghese Z, Ruan XZ, \& Chen Y (2016) Inflammatory stress sensitizes the liver to atorvastatin-induced injury in ApoE-/- mice. PLoS One, 11, e0159512.

[108] Jang HJ, Hong EM, Kim M, Kim JH, Jang J, Park SW, Byun HW, Koh DH, Choi MH, Kae SH, \& Lee J (2016) Simvastatin induces heme oxygenase-1 via NF-E2-related factor 2 (Nrf2) activation through ERK and PI3K/Akt pathway in colon cancer. Oncotarget, 7, 46219-46229.

[109] Ferraro SA, Astort F, Yakisich JS, \& Tasat DR (2016) Particulate matter cytotoxicity in cultured SH-SY5Y cells is modulated by simvastatin: Toxicological assessment for oxidative damage. Neurotoxicology, 53, 108-114.

[110] Yeh YH, Kuo CT, Chang GJ, Chen YH, Lai YJ, Cheng ML, \& Chen WJ (2015) Rosuvastatin suppresses atrial tachycardia-induced cellular remodeling via Akt/Nrf2/ heme oxygenase-1 pathway. J Mol Cell Cardiol, 82, 84-92.

[111] Hsieh CH, Rau CS, Hsieh MW, Chen YC, Jeng SF, Lu TH, \& Chen SS (2008) Simvastatin-induced heme oxygenase1 increases apoptosis of Neuro 2A cells in response to glucose deprivation. Toxicol Sci, 101, 112-121.

[112] Conservative Iron Chelation as a Disease-modifying Strategy in Parkinson's Disease (FAIRPARKII), https:// clinicaltrials.gov/show/NCT02655315 Verified May 19 2017. Accessed October 1, 2017.

[113] Study of Parkinson's Early Stage With Deferiprone (SKY), https://clinicaltrials.gov/show/NCT02728843 Verified September 26 2017. Accessed October 1, 2017.

[114] Rey NL, Steiner JA, Maroof N, Luk KC, Madaj Z, Trojanowski JQ, Lee VM, \& Brundin P (2016) Widespread transneuronal propagation of $\alpha$-synucleinopathy triggered in olfactory bulb mimics prodromal Parkinson's disease. J Exp Med, 213, 1759-1778.

[115] Luk KC, Kehm VM, Zhang B, O'Brien P, Trojanowski JQ, \& Lee VM (2012) Intracerebral inoculation of pathological $\alpha$-synuclein initiates a rapidly progressive neurodegenerative $\alpha$-synucleinopathy in mice. J Exp Med, 209, 975-986.

[116] George S, Rey NL, Reichenbach N, Steiner JA, \& Brundin $P$ (2013) $\alpha$-Synuclein: the long distance runner. Brain Pathol, 23, 350-357.

[117] Brundin P, Ma J, \& Kordower JH (2016) How strong is the evidence that Parkinson's disease is a prion disorder? Curr Opin Neurol 29, 459-466.

[118] Braak H, \& Del Tredici K (2017) Neuropathological staging of brain pathology in sporadic Parkinson's disease: Separating the wheat from the chaff. J Parkinsons Dis, 7, S73-S87.

[119] Bar-On P, Crews L, Koob AO, Mizuno H, Adame A, Spencer B, \& Masliah E (2008) Statins reduce neuronal alpha-synuclein aggregation in in vitro models of Parkinson's disease. J Neurochem, 105, 1656-1667.

[120] Bosco DA, Fowler DM, Zhang Q, Nieva J, Powers ET, Wentworth P Jr, Lerner RA, \& Kelly JW (2006) Elevated levels of oxidized cholesterol metabolites in Lewy body disease brains accelerate alpha-synuclein fibrilization. Nat Chem Biol, 2, 249-253.

[121] Eriksson I, Nath S, Bornefall P, Giraldo AM, \& Öllinger K (2017) Impact of high cholesterol in a Parkinson's disease model: Prevention of lysosomal leakage versus stimulation of $\alpha$-synuclein aggregation. Eur J Cell Biol, 96, 99-109.

[122] Koob AO, Ubhi K, Paulsson JF, Kelly J, Rockenstein E, Mante M, Adame A, \& Masliah E (2010) Lovastatin ameliorates alpha-synuclein accumulation and oxidation in transgenic mouse models of alpha-synucleinopathies. Exp Neurol, 221, 267-274.

[123] Klegeris A, Giasson BI, Zhang H, Maguire J, Pelech S, \& McGeer PL (2006) Alpha-synuclein and its diseasecausing mutants induce ICAM-1 and IL-6 in human astrocytes and astrocytoma cells. FASEB J, 20, 2000-2008.

[124] Sanchez-Guajardo V, Febbraro F, Kirik D, \& RomeroRamos M (2010) Microglia acquire distinct activation profiles depending on the degree of alpha-synuclein neuropathology in a rAAV based model of Parkinson's disease. PLoS One, 5, e8784.

[125] Gan L, Vargas MR, Johnson DA, \& Johnson JA (2012) Astrocyte-specific overexpression of Nrf2 delays motor pathology and synuclein aggregation throughout the CNS in the alpha-synuclein mutant (A53T) mouse model. J Neurosci, 32, 17775-17787.

[126] Chen J, Costa LG, \& Guizzetti M (2011) Retinoic acid isomers up-regulate ATP binding cassette A1 and G1 and cholesterol efflux in rat astrocytes: implications for their therapeutic and teratogenic effects. J Pharmacol Exp Ther, 338, 870-878.

[127] Kang SY, Lee SB, Kim HJ, Kim HT, Yang HO, \& Jang W (2017) Autophagic modulation by rosuvastatin prevents rotenone-induced neurotoxicity in an in vitro model of Parkinson's disease. Neurosci Lett, 642, 20-26.

[128] Paul R, Choudhury A, \& Borah A (2015) Cholesterol A putative endogenous contributor towards Parkinson's disease. Neurochem Int, 90, 125-133.

[129] Saito T, Nito C, Ueda M, Inaba T, Kamiya F, Muraga K, Katsura K, \& Katayama Y (2014) Continuous oral administration of atorvastatin ameliorates brain damage after transient focal ischemia in rats. Life Sci, 94, 106-114.

[130] Allen Reish HE, \& Standaert DG (2015) Role of $\alpha$ synuclein in inducing innate and adaptive immunity in Parkinson disease. J Parkinsons Dis, 5, 1-19. 
[131] Davies JT, Delfino SF, Feinberg CE, Johnson MF, Nappi VL, Olinger JT, Schwab AP, \& Swanson HI (2016) Current and emerging uses of statins in clinical therapeutics: a review. Lipid Insights, 9, 13-29.

[132] Bedi O, Dhawan V, Sharma PL, \& Kumar P (2016) Pleiotropic effects of statins: new therapeutic targets in drug design. Naunyn Schmiedebergs Arch Pharmacol, 389, 695-712.

[133] Tousoulis D, Psarros C, Demosthenous M, Patel R, Antoniades C, \& Stefanadis C (2014) Innate and adaptive inflammation as a therapeutic target in vascular disease: the emerging role of statins. J Am Coll Cardiol, 63, 24912502 .

[134] Zhang X, Tao Y, Wang J, Garcia-Mata R, \& MarkovicPlese S (2013) Simvastatin inhibits secretion of Th17-polarizing cytokines and antigen presentation by DCs in patients with relapsing remitting multiple sclerosis. Eur J Immunol, 43, 281-289.

[135] Chataway J, Schuerer N, Alsanousi A, Chan D, MacManus D, Hunter K, Anderson V, Bangham CR, Clegg S, Nielsen C, Fox NC, Wilkie D, Nicholas JM, Calder VL, Greenwood J, Frost C, \& Nicholas R (2014) Effect of high-dose simvastatin on brain atrophy and disability in secondary progressive multiple sclerosis (MS-STAT): a randomised, placebo-controlled, phase 2 trial. Lancet, 383, 2213-2221.

[136] Soubrier M, Pei J, Durand F, Gullestad L, \& John A (2017) Concomitant use of statins in tocilizumab-treated patients with rheumatoid arthritis: A post hoc analysis. Rheumatol Ther, 4, 133-149.

[137] Inanc MT, Kalay N, Heyit T, Ozdogru I, Kaya MG, Dogan A, Duran M, Kasapkara HA, Gunebakmaz O, Borlu M, Yarlioglues M, \& Oguzhan A (2010) Effects of atorvastatin and lisinopril on endothelial dysfunction in patients with Behçet's disease. Echocardiography, 27, 997-1003.

[138] Duan C, Du ZD, Wang Y, \& Jia LQ (2014) Effect of pravastatin on endothelial dysfunction in children with medium to giant coronary aneurysms due to Kawasaki disease. World J Pediatr, 10, 232-237.

[139] Suda K, Tahara N, Honda A, Yoshimoto H, Kishimoto S, Kudo Y, Kaida H, Abe T, Ueno T, \& Fukumoto Y (2015) Statin reduces persistent coronary arterial inflammation evaluated by serial 18 fluorodeoxyglucose positron emission tomography imaging long after Kawasaki disease. Int J Cardiol, 179, 61-62.

[140] Benner EJ, Mosley RL, Destache CJ, Lewis TB, JacksonLewis V, Gorantla S, Nemachek C, Green SR, Przedborski S, \& Gendelman HE (2004) Therapeutic immunization protects dopaminergic neurons in a mouse model of Parkinson's disease. Proc Natl Acad Sci USA, 101, 94359440.

[141] Benner EJ, Banerjee R, Reynolds AD, Sherman S, Pisarev VM, Tsiperson V, Nemachek C, Ciborowski P, Przedborski S, Mosley RL, \& Gendelman HE (2008) Nitrated alpha-synuclein immunity accelerates degeneration of nigral dopaminergic neurons. PLoS One, 3, e1376.

[142] Martin HL, Santoro M, Mustafa S, Riedel G, Forrester JV, \& Teismann P (2016) Evidence for a role of adaptive immune response in the disease pathogenesis of the MPTP mouse model of Parkinson's disease. Glia, 64, 386-395.

[143] Reynolds AD, Banerjee R, Liu J, Gendelman HE, \& Mosley RL (2007) Neuroprotective activities of $\mathrm{CD} 4+\mathrm{CD} 25+$ regulatory $\mathrm{T}$ cells in an animal model of Parkinson's disease. J Leukoc Biol, 82, 1083-1094.

[144] Mosley RL, Benner EJ, Kadiu I, Thomas M, Boska MD, Hasan K, Laurie C, \& Gendelman HE (2006) Neu- roinflammation, oxidative stress and the pathogenesis of Parkinson's disease. Clin Neurosci Res, 6, 261-281.

[145] Reynolds AD, Stone DK, Hutter JA, Benner EJ, Mosley RL, \& Gendelman HE (2010) Regulatory T cells attenuate Th17 cell-mediated nigrostriatal dopaminergic neurodegeneration in a model of Parkinson's disease. J Immunol, 184, 2261-2271.

[146] Hutter-Saunders JA, Mosley RL, \& Gendelman HE (2011) Pathways towards an effective immunotherapy for Parkinson's disease. Expert Rev Neurother, 11, 1703-1715.

[147] Kannarkat GT, Boss JM, \& Tansey MG (2013) The role of innate and adaptive immunity in Parkinson's disease. J Parkinsons Dis, 3, 493-514.

[148] Gendelman HE, \& Mosley RL (2015) A perspective on roles played by innate and adaptive immunity in the pathobiology of neurodegenerative disorders. J Neuroimmune Pharmacol, 10, 645-650.

[149] Kosloski LM, Ha DM, Hutter JA, Stone DK, Pichler MR, Reynolds AD, Gendelman HE, \& Mosley RL (2010) Adaptive immune regulation of glial homeostasis as an immunization strategy for neurodegenerative diseases. J Neurochem, 114, 1261-1276.

[150] Olson KE, Kosloski-Bilek LM, Anderson KM, Diggs BJ, Clark BE, Gledhill JM Jr, Shandler SJ, Mosley RL, \& Gendelman HE (2015) Selective VIP receptor agonists facilitate immune transformation for dopaminergic neuroprotection in MPTP-intoxicated mice. J Neurosci, 35, 16463-16478

[151] Brahmachari S, \& Pahan K (2010) Myelin basic protein priming reduces the expression of Foxp3 in T cells via nitric oxide. J Immunol, 184, 1799-1809.

[152] Hernández-Romero MC, Argüelles S, Villarán RF, de Pablos RM, Delgado-Cortés MJ, Santiago M, Herrera AJ, Cano J, \& Machado A (2008) Simvastatin prevents the inflammatory process and the dopaminergic degeneration induced by the intranigral injection of lipopolysaccharide. J Neurochem, 105, 445-459.

[153] Wu H, Lu D, Jiang H, Xiong Y, Qu C, Li B, Mahmood A, Zhou D, \& Chopp M (2008) Simvastatin-mediated upregulation of VEGF and BDNF, activation of the PI3K/Akt pathway, and increase of neurogenesis are associated with therapeutic improvement after traumatic brain injury. J Neurotrauma, 25, 130-139.

[154] Han X, Yang N, Xu Y, Zhu J, Chen Z, Liu Z, Dang G, \& Song C (2011) Simvastatin treatment improves functional recovery after experimental spinal cord injury by upregulating the expression of BDNF and GDNF. Neurosci Lett, 487, 255-259.

[155] Yang D, Han Y, Zhang J, Chopp M, \& Seyfried DM (2012) statins enhance expression of growth factors and activate the PI3K/Akt-mediated signaling pathway after experimental intracerebral hemorrhage. World J Neurosci, 2, 74-80.

[156] Churchward MA, \& Todd KG (2014) Statin treatment affects cytokine release and phagocytic activity in primary cultured microglia through two separable mechanisms. Mol Brain, 7, 85.

[157] Rana DG, Patel AK, Joshi CG, Jhala MK, \& Goyal RK (2014) Alteration in the expression of exon IIC transcripts of brain-derived neurotrophic factor gene by simvastatin [correction of simvastain] in chronic mild stress in mice: a possible link with dopaminergic pathway. Can J Physiol Pharmacol, 92, 985-992.

[158] Wang C, Chen T, Li G, Zhou L, Sha S, \& Chen L (2015) Simvastatin prevents $\beta$-amyloid(25-35)-impaired 
neurogenesis in hippocampal dentate gyrus through $\alpha 7 n A C h R-d e p e n d e n t$ cascading PI3K-Akt and increasing BDNF via reduction of farnesyl pyrophosphate. $\mathrm{Neu}$ ropharmacology, 97, 122-132.

[159] Gao K, Wang G, Wang Y, Han D, Bi J, Yuan Y, Yao T, Wan Z, Li H, \& Mei X (2015) Neuroprotective effect of simvastatin via inducing the autophagy on spinal cord injury in the rat model. Biomed Res Int, 2015, 260161.

[160] Gao K, Shen Z, Yuan Y, Han D, Song C, Guo Y, \& Mei X (2016) Simvastatin inhibits neural cell apoptosis and promotes locomotor recovery via activation of $\mathrm{Wnt} / \beta$-catenin signaling pathway after spinal cord injury. J Neurochem, 138, 139-149.

[161] Zhang C, Wu JM, Liao M, Wang JL, \& Xu CJ (2016) The ROCK/GGTase pathway are essential to the proliferation and differentiation of neural stem cells mediated by simvastatin. J Mol Neurosci, 60, 474-485.

[162] Guo Q, Liu C, Hai B, Ma T, Zhang W, Tan J, Fu X, Wang H, Xu Y, \& Song C (2017) Chitosan conduits filled with simvastatin/Pluronic F-127 hydrogel promote peripheral nerve regeneration in rats. J Biomed Mater Res B Appl Biomater. doi: 10.1002/jbm.b. 33890

[163] Zhang J, Mu X, Breker DA, Li Y, Gao Z, \& Huang Y (2017) Atorvastatin treatment is associated with increased BDNF level and improved functional recovery after atherothrombotic stroke. Int J Neurosci, 127, 92-97.

[164] Decressac M, Kadkhodaei B, Mattsson B, Laguna A, Perlmann T, \& Björklund A (2012) $\alpha$-Synuclein-induced down-regulation of Nurr1 disrupts GDNF signaling in nigral dopamine neurons. Sci Transl Med, 4, 163ra156.

[165] Roy A, Jana M, Kundu M, Corbett GT, Rangaswamy SB, Mishra RK, Luan CH, Gonzalez FJ, \& Pahan K (2015) HMG-CoA reductase inhibitors bind to PPAR $\alpha$ to upregulate neurotrophin expression in the brain and improve memory in mice. Cell Metab, 22, 253-265.

[166] Castro AA, Wiemes BP, Matheus FC, Lapa FR, Viola GG, Santos AR, Tasca CI, \& Prediger RD (2013) Atorvastatin improves cognitive, emotional and motor impairments induced by intranasal 1-methyl-4-phenyl1,2,3,6-tetrahydropyridine (MPTP) administration in rats, an experimental model of Parkinson's disease. Brain Res, 1513, 103-116.

[167] Tan W, Xue-bin C, Tian Z, Xiao-wu C, Pei-pei H, Zhi-bin C, \& Bei-sha T (2016) Effects of simvastatin on the expression of inducible nitric oxide synthase and brain-derived neurotrophic factor in a lipopolysaccharide-induced rat model of Parkinson disease. Int J Neurosci, 126, 278-286.

[168] US Preventive Services Task Force, Bibbins-Domingo K, Grossman DC, Curry SJ, Davidson KW, Epling JW Jr, García FA, Gillman MW, Kemper AR, Krist AH, Kurth AE, Landefeld CS, LeFevre ML, Mangione CM, Phillips WR, Owens DK, Phipps MG, \& Pignone MP (2016) Statin use for the primary prevention of cardiovascular disease in adults: US Preventive Services Task Force Recommendation Statement. JAMA, 316, 1997-2007.

[169] "Cardiovascular disease: Risk assessment and reduction, including lipid modification at www.nice.org.uk". Last updated, September 2016. Assessed 1 October 2017.

[170] McGuinness B, O'Hare J, Craig D, Bullock R, Malouf $\mathrm{R}$, \& Passmore P (2013) Cochrane review on 'Statins for the treatment of dementia'. Int J Geriatr Psychiatry, 28, 119-126.

[171] McGuinness B, Craig D, Bullock R, Malouf R, \& Passmore P (2014) Statins for the treatment of dementia. Cochrane Database Syst Rev, CD007514.
[172] Deck BL, Rick J, Xie SX, Chen-Plotkin A, Duda JE, Morley JF, Chahine LM, Dahodwala N, Trojanowski JQ, \& Weintraub D (2017) Statins and cognition in Parkinson's disease. J Parkinsons Dis. doi: 10.3233/JPD-171113

[173] Swanson CR, Li K, Unger TL, Gallagher MD, Van Deerlin VM, Agarwal P, Leverenz J, Roberts J, Samii A, Gross RG, Hurtig H, Rick J, Weintraub D, Trojanowski JQ, Zabetian C, \& Chen-Plotkin AS (2015) Lower plasma apolipoprotein A1 levels are found in Parkinson's disease and associate with apolipoprotein A1 genotype. Mov Disord, 30, 805-812.

[174] Swanson CR, Berlyand Y, Xie SX, Alcalay RN, Chahine LM, \& Chen-Plotkin AS (2015) Plasma apolipoprotein A1 associates with age at onset and motor severity in early Parkinson's disease patients. Mov Disord, 30, 1648-1656.

[175] de Lau LM, Koudstaal PJ, Hofman A, \& Breteler MM (2006) Serum cholesterol levels and the risk of Parkinson's disease. Am J Epidemiol, 164, 998-1002.

[176] Wolozin B, Wang SW, Li NC, Lee A, Lee TA, \& Kazis LE (2007) Simvastatin is associated with a reduced incidence of dementia and Parkinson's disease. BMC Med, $\mathbf{5}, 20$.

[177] Wahner AD, Bronstein JM, Bordelon YM, \& Ritz B (2008) Statin use and the risk of Parkinson disease. Neurology 70(16 Pt 2), 1418-1422.

[178] Huang X, Chen H, Miller WC, Mailman RB, Woodard JL, Chen PC, Xiang D, Murrow RW, Wang YZ, \& Poole C (2007) Lower low-density lipoprotein cholesterol levels are associated with Parkinson's disease. Mov Disord, 22, 377-381.

[179] Becker C, Jick SS, \& Meier CR (2008) Use of statins and the risk of Parkinson's disease: a retrospective case-control study in the UK. Drug Safety, 31, 399-407.

[180] Hu G, Antikainen R, Jousilahti P, Kivipelto M, \& Tuomilehto J (2008) Total cholesterol and the risk of Parkinson disease. Neurology, 70, 1972-1979.

[181] Mutez E, Duhamel A, Defebvre L, Bordet R, Destée A, \& Kreisler A (2009) Lipid-lowering drugs are associated with delayed onset and slower course of PD. Pharmacol Res, 60, 41-45.

[182] Huang X, Auinger P, Eberly S, Oakes D, Schwarzschild M, Ascherio A, Mailman R, Chen H; Parkinson Study Group DATATOP Investigators (2011) Serum cholesterol and the progression of Parkinson's disease: results from DATATOP. PLoS One, 6, e22854.

[183] Gao X, Simon KC, Schwarzschild MA, \& Ascherio A (2012) Prospective study of statin use and risk of Parkinson disease. Arch Neurol, 69, 380-384.

[184] Undela K, Gudala K, Malla S, \& Bansal D (2013) Statin use and risk of Parkinson's disease: a meta-analysis of observational studies. J Neurol, 260, 158-165.

[185] Friedman B, Lahad A, Dresner Y, \& Vinker S (2013) Longterm statin use and the risk of Parkinson's disease. Am J Manag Care, 19, 626-632.

[186] Lee Y-C, Lin C-H, Wu R-M, Lin M-S, Lin J-W, Chang C-H, \& Lai M-S (2013) Discontinuation of statin therapy associates with Parkinson disease: a population-based study. Neurology, 81, 410-416.

[187] Tan EK, \& Tan LC (2013) Holding on to statins in Parkinson disease. Neurology, 81, 406-407.

[188] Huang X, Alonso A, Guo X, Umbach DM, Lichtenstein ML, Ballantyne CM, Mailman RB, Mosley TH, \& Chen H (2015) Statins, plasma cholesterol, and risk of Parkinson's disease: a prospective study. Mov Disord, 30, 552-559. 
[189] Bai S, Song Y, Huang X, Peng L, Jia J, Liu Y, \& Lu H (2016) Statin use and the risk of Parkinson's disease: An updated meta-analysis. PLoS One, 11, e0152564.

[190] Sheng Z, Jia X, \& Kang M (2016) Statin use and risk of Parkinson's disease: A meta-analysis. Behav Brain Res, 309, 29-34.

[191] Clark LT, Maki KC, Galant R, Maron DJ, Pearson TA, \& Davidson MH (2006) Ethnic differences in achievement of cholesterol treatment goals. Results from the National Cholesterol Education Program Evaluation Project Utilizing Novel E-Technology II. J Gen Intern Med, 21, 320-326.

[192] Yood MU, McCarthy BD, Kempf J, Kucera GP, Wells K, Oliveria S, \& Stang P (2006) Racial differences in reaching target low-density lipoprotein goal among individuals treated with prescription statin therapy. Am Heart J, 152, 777-784.

[193] Sterling NW, Lichtenstein M, Lee EY, Lewis MM, Evans A, Eslinger PJ, Du G, Gao X, Chen H, Kong L, \& Huang X (2016) Higher plasma LDL-cholesterol is associated with preserved executive and fine motor functions in Parkinson's disease. Aging Dis, 7, 237-245.

[194] Liu G, Sterling NW, Kong L, Lewis MM, Mailman RB, Chen H, Leslie D, \& Huang X (2017) Statins may facilitate Parkinson's disease: Insight gained from a large, national claims database. Mov Disord, 32, 913-917.

[195] Rozani V, Giladi N, El-Ad B, Gurevich T, Tsamir J, Hemo B, \& Peretz C (2017) Statin adherence and the risk of Parkinson's disease: A population-based cohort study. PLoS One, 12, e 0175054

[196] Bykov K, Yoshida K, Weisskopf MG, \& Gagne JJ (2017) Confounding of the association between statins and Parkinson disease: systematic review and meta-analysis. Pharmacoepidemiol Drug Saf, 26, 294-300.

[197] Shrank WH, Patrick AR, \& Brookhart MA (2011) Healthy user and related biases in observational studies of preventive interventions: a primer for physicians. J Gen Intern Med, 26, 546-550.

[198] Swallow DM, Lawton MA, Grosset KA, Malek N, Klein J, Baig F, Ruffmann C, Bajaj NP, Barker RA, Ben-Shlomo Y, Burn DJ, Foltynie T, Morris HR, Williams N, Wood NW, Hu MT, \& Grosset DG (2016) Statins are underused in recent-onset Parkinson's disease with increased vascular risk: findings from the UK Tracking Parkinson's and Oxford Parkinson's Disease Centre (OPDC) discovery cohorts. J Neurol Neurosurg Psychiatry, 87, 1183-1190.

[199] Chan D, Binks S, Nicholas JM, Frost C, Cardoso MJ, Ourselin S, Wilkie D, Nicholas R, \& Chataway J (2017) Effect of high-dose simvastatin on cognitive, neuropsychiatric, and health-related quality-of-life measures in secondary progressive multiple sclerosis: secondary analyses from the MS-STAT randomised, placebo-controlled trial. Lancet Neurol, 16, 591-600.

[200] Saeedi Saravi SS, Saeedi Saravi SS, Arefidoust A, \& Dehpour AR (2017) The beneficial effects of HMG-CoA reductase inhibitors in the processes of neurodegeneration. Metab Brain Dis, 32, 949-965.

[201] Ciurleo R, Bramanti P, \& Marino S (2014) Role of statins in the treatment of multiple sclerosis. Pharmacol Res, 87, 133-143.

[202] Wong B, Lumma WC, Smith AM, Sisko JT, Wright SD, \& Cai TQ (2001) Statins suppress THP-1 cell migration and secretion of matrix metalloproteinase 9 by inhibiting geranylgeranylation. J Leukoc Biol, 69, 959-962.

[203] Ganné F, Vasse M, Beaudeux JL, Peynet J, François A, Mishal Z, Chartier A, Tobelem G, Vannier JP, Soria J, \& Soria C (2000) Cerivastatin, an inhibitor of HMG-CoA reductase, inhibits urokinase/urokinasereceptor expression and MMP-9 secretion by peripheral blood monocytes-a possible protective mechanism against atherothrombosis. Thromb Haemost, 84, 680-688.

[204] Sena A, Pedrosa R, \& Morais MG (2007) Beneficial effect of statins in multiple sclerosis: is it dose-dependent? Atherosclerosis 191, 462.

[205] MS Drug Treatment Costs Start the Year Headed Up, https://multiplesclerosisnewstoday.com/2017/01/13/msdrug-treatment-costs-start-year-headed-up/Published January 13, 2017. Accessed October 1, 2017.

[206] £6m statin trial raises hope drug can be used to treat multiple sclerosis, https://www.theguardian.com/society/2017/ may/09/statin-trial-raises-hope-drug-can-be-used-to-treat -multiple-sclerosis-disability-progressive-ms, Published May 9, 2017. Accessed October 1, 2017.

[207] Su W, Kansal A, Vicente C, Deniz B, \& Sarda S (2016) The cost-effectiveness of delayed-release dimethyl fumarate for the treatment of relapsing-remitting multiple sclerosis in Canada. J Med Econ, 19, 718-727.

[208] Bozkaya D, Livingston T, Migliaccio-Walle K, \& Odom T (2017) The cost-effectiveness of disease-modifying therapies for the treatment of relapsing-remitting multiple sclerosis. J Med Econ, 20, 297-302.

[209] Soini E, Joutseno J, \& Sumelahti ML (2017) Cost-utility of First-line Disease-modifying Treatments for RelapsingRemitting Multiple Sclerosis. Clin Ther, 39, 537-557.e10.

[210] Shih T, Wakeford C, Meletiche D, Sussell J, Chung A, Liu Y, Shim JJ, \& Lakdawalla D (2016) Reconsidering the economic value of multiple sclerosis therapies. Am J Manag Care, 22, e368-e374.

[211] Santos R, Ursu O, Gaulton A, Bento AP, Donadi RS, Bologa CG, Karlsson A, Al-Lazikani B, Hersey A, Oprea TI, \& Overington JP (2017) A comprehensive map of molecular drug targets. Nat Rev Drug Discov, 16, 19-34. 